-

\title{
Geologic Appraisal of
}

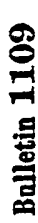

Dimension-Stone

Deposits

G E O L O G I C A L S U RVEY BULILTI N 1_1:09

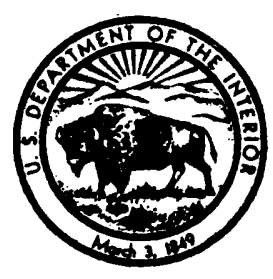

QE 75

no. $1109-1110 B$

QQS

$0 . b$ 
Geologic Appraisal of Dimension-Stone Deposits

By L. W. CURRIER

GEOLOGICAL SU RVEY B U L L E T I N 1109

A background and field guide

for the geologic study of

commercial stones

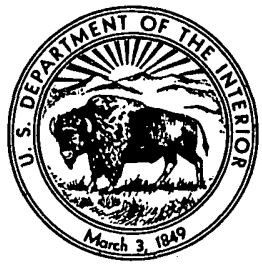




\title{
UNITED STATES DEPARTMENT OF THE INTERIOR
}

FRED A. SEATON, Secretary

\author{
GEOLOGIGAL SURVEY
}

Thomas B. Nolan, Director

The U.S. Geological Survey Library has cataloged this publication as follows:

\section{Currier, Louis Wade, 1890-}

Geologic appraisal of dimension-stone deposits. Washington, U.S. Govt. Print. Off., 1960.

iv, 78 p. illus., diagrs., tables. $24 \mathrm{~cm}$. (U.S. Geological Survey. Bulletin 1109)

A background and field guide for the geologic study of commercial stones.

"Selected references": p. 75-76.

1. Stone. 2. Petrology. 3. Geology-Fieldwork. I. Title. (Series) 


\section{CONTENTS}

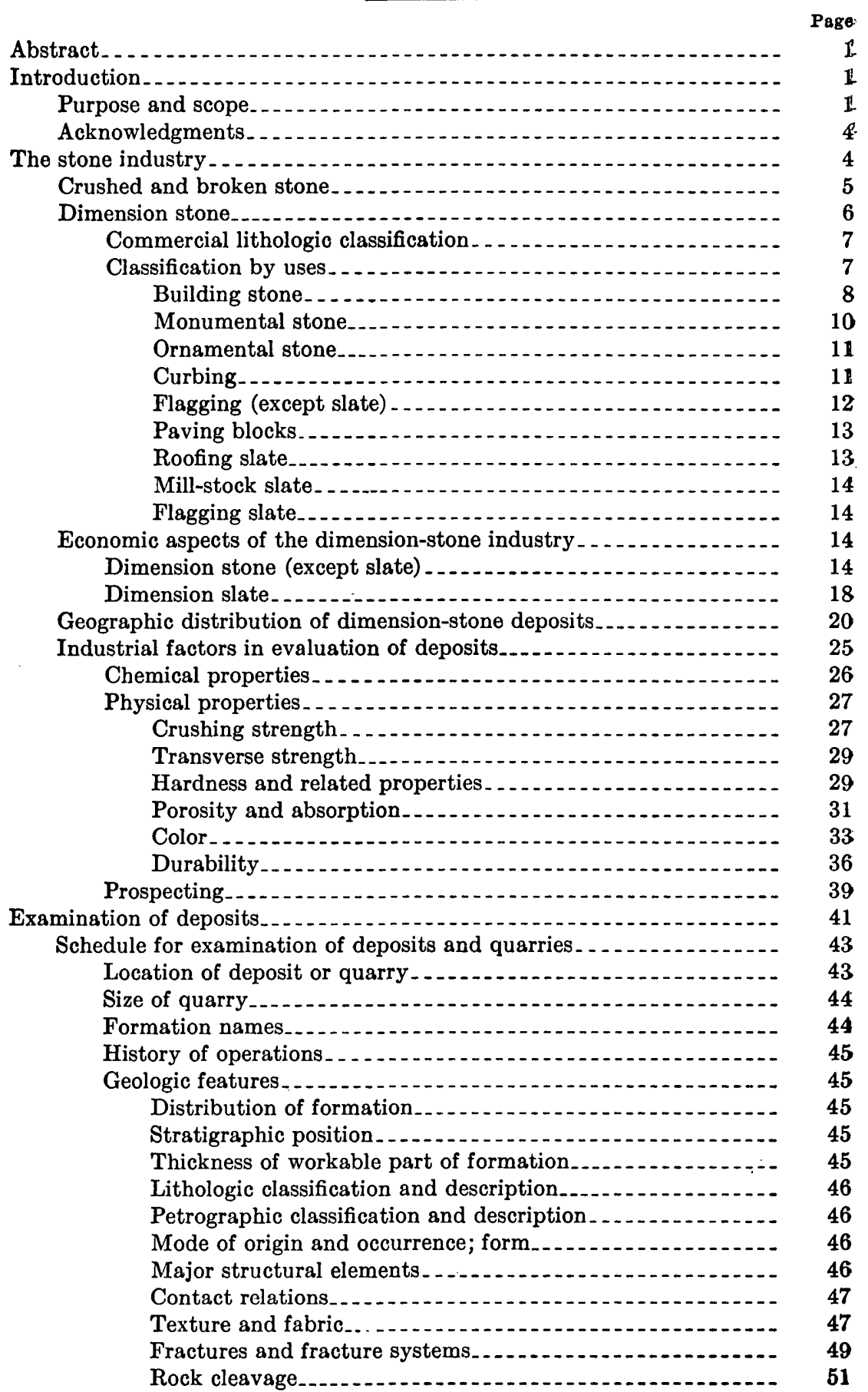


Examination of deposits-Continued

Schedule for examinations of deposits and quarries-Continued Geologic features-Continued

Veins and dikes

Inclusions and segregation

Overburd

Weathering

Physical weathering

Chemical weathering .............

Industrial fertures...

Classification

Use of the stone

Topography ............

Accessibility

Operating facility

Workability of the stone

Color

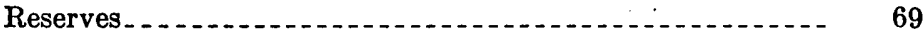

Standard definitions of terms relating to natural building stones......

List of standard methods of test and specification

Selected references._.

Index ...

\section{ILLUSTRATIONS}

Plate 1. Lithologic provinces of the United States as related to occurrences and production of principal types of dimension stones. In pocket

Pago

2. Granite quarry showing "headers," dike, and sheeting- Facing

3. A, Granite quarry showing horizontal sheets and increase in thickness with depth; $B$, Granite quarry showing relation of thin sheeting to topographic surface

4. Pit quarry in granite showing development of lenticular sheets. .............. Following

5. Face in slate quarry developed along bedding........ Facing

6. Zone of quartz veinlets crossing cleavage of slate..... Facing

7. $A$, Pit quarry in horizontally bedded sandstone; $B$, Pit quarry in horizontally bedded limestone.................. Facing

Figure 1. Production of dimension stone, except slate, 1910-56........

2. Production of dimension slate, 1910-56

\section{TABLES}

TABLE 1. Construction stone sold or used by producers in the United States, 1956.

2. Dimension stone sold or used by producers in the United States, 1956 .

3. Production of dimension slate sold by producers in the United States, 1956

4. Percentage increases in production of dimension stone in the United States, 1919-29 and 1944-55 


\title{
GEOLOGIC APPRAISAL OF DIMENSION-STONE DEPOSITS
}

\author{
By L. W. Currier
}

\begin{abstract}
The construction stone industry comprises two major branches-dimension stone and crushed and broken stone. For purposes of geologic appraisal, deposits of these two categories should be treated separately, because they differ widely in use, mode of development, and exploitation. Deposits of dimension stones are subjected to much greater selectivity with respect to physical properties, uniformity, and modes of occurrence; these demand a much more critical and detailed study of geologic and mineralogic features.

Dimension stones are classified commercially in seven principal varietiesgranite, limestone, marble, sandstone, slate, greenstone, and basalt; commercial definitions of these are much broader and more inclusive than are the petrographic definitions. Each type presents certain distinctive aspects of occurrence and properties as related to geologic features. Dimension stones except slate are classified further, for statistical purposes, according to use as building, monumental, paving blocks, curbing, and flagging. Building stone constitutes about 80 percent (quantity) of dimension stone produced, and monumental stone about 10 percent. The general level of production since World War II is about half that of recorded earlier peak productions, a decline that reflects, in part, changes in construction practice for large buildings and, in part, substitution of manufactured materials.

The appraisal of deposits of dimension stones involves factors that are, in part, peculiar to the economy of the industry, but in large part are of a geologic and mineralogic nature. The suitability of a deposit for development is dependent in large measure upon major geologic structural features; the durability of the quarry product is determined by physical and chemical properties which, in turn, are functions of mineralogic composition, and textural and certain minor structural features. The acquiring and interpretation of pertinent geologic and mineralogic data fall within the appropriate functions of the fleld geologist. This paper outlines and discusses the relevancy of such data to geologic appralsal.
\end{abstract}

\section{INTRODUCTION}

\section{PURPOSE AND SCOPE}

Stone has been used throughout historic time as a major construction material because it affords strength, durability, architectural adaptability, and aesthetic satisfaction. No other type of material combines all these qualities. Resources are boundless, and workable deposits of one type or another may be found almost everywhere that needs are felt. Quarrying of stone must have been practiced 
as soon as man was able to devise adequate tools for breaking and shaping blocks, but even before that time loose slabs and boulders furnished good materials for construction of crude shelters and defensive walls.

With the development of quarries and quarrying arts came selectivity, for it was soon realized that some types of stone could be extracted and fashioned with greater facility than others, that some types would afford larger or sounder blocks, and that some would afford materials of greater architectural and aesthetic merit. Even deposits of the same type were found to differ among themselves in respect to these qualities. Such differences in properties and qualities are essentially of geologic and mineralogic nature, though selectivity was in early times based largely upon experience rather than upon critical knowledge of geologic modes of occurrence and structures, or of mineralogic composition and textures. Geologic selectivity in its broadest aspects, with respect to needs, uses, and availability, is the basic philosophy of this present treatment of appraisal. The subject is limited to dimension stones, because fragmented stone presents distinctive aspects of use, exploration, and exploitation.

This report was planned and designed originally to fit the needs of the field geologist who is engaged in general geologic mapping of an area. His function is ordinarily to report on the broad economic aspects of rock formations and mineral occurrences, rather than on close quantitative appraisals or matters of technical development. He provides a preliminary reconnaissance to guide consultants, engineers, and operators in more specialized industrial studies, and he may have no special commodity knowledge beyond that resident in sound and general geologic training.

As the treatment developed, however, it seemed desirable to bridge the gap between the geologist and the stone specialist by correlating the field approach of the geologist with the technical interests of the operator. To that end, this volume attempts to provide the geologist with the broader technical aspects of the stone industry that derive from geologic features. At the same time it is hoped that the specialist, consultant, and operator may find various parts of the report useful and informative, even if only in the putting together in one volume of certain kinds of technical knowledge that have, in large measure, been obtained from various standard sources and from consultations with many producers and consumers. That these objectives have been attained to some degree seems indicated by the comments of reviewers in both the geologic and industrial fields.

Personal field and laboratory experience spread intermittently through more than 20 years has furnished the stimulation and background for this effort. 
Emphasis and discrimination have been attempted throughoutemphasis on strictly geologic features pertinent to a field study of stone deposits, and discrimination as to the proper role of the geologist in such a study. It is hoped that the geologist will find answers to the questions of what he should do and what he should not be expected to do. To that end, the section on "The stone industry" has been devised to give an industrial and economic background that will orient him with respect to the comparative importance of the industry in the field of economic geology and to the physical properties that characterize a satisfactory dimension stone: The section on "Examination of deposits" is a schedule to be followed, whether deposits are developed or undeveloped. It provides a sufficient explanation of each item to guide the geologist in making certain observations in the field and to understand reasons for making them; thus they are tied into the developmental and industrial aspects of the quarrying industry. These explanations are keyed referentially into the general matter of the section on "The stone industry." For this reason there is some amount of repetition which, the writer believes, lends emphasis to the specific items and coherence between the two sections.

It is hoped also that the consulting geologist, who carries on from the work of the general field geologist, will find some guidance in his task of examining properties, old quarries, and undeveloped areas. His functions involve details necessarily beyond the scope of a field geologist during routine mapping. They carry his studies into the quarrying and industrial operations, thus bridging the hiatus between the field geologist and the producer. It is hoped further that the producer may himself become more aware of the various ways in which the science of geology pertains to his own problems of exploration and development. He may accordingly be guided in judging when to seek technical geologic advice and how to evaluate data so obtained.

Many excellent books and governmental reports have been published on various phases of the stone industry. Some that are of general interest are cited in the list of references and selected bibliography at the end of this report. The list does not include many publications that are devoted primarily to descriptions of districts and quarries; these comprise for the most part publications by various State geological surveys, which contain a wealth of specific data, but ordinarily do little to orient the field geologist in respect to details of observation and practical appraisal of a deposit. The writer feels that most of the present work is not repetitive of earlier reports, but is supplementary to them. To that end descriptions of deposits and quarries are avoided, and the text concentrates on 
properties, geologic and economic features, and industrial aspects of general nature that are directly related in the broadest sense to geologic modes of occurrence.

\section{ACRNOWLEDGMENTS}

The writer finds it impractical to attempt to list all personal sources of information, help, and advice, for contacts with individuals in the industry who have aided materially in one way or another have been numerous. Operators have been most generous and helpful by giving ready access to quarries and by freely discussing and advising on various aspects of the subject. In particular the writer has profited by his contacts with members of the Committee on Natural Building Stones of the American Society for Testing Materials, on which he has served for several years as chairman.

Especial acknowledgments are due to Ralph A. Fletcher of the H. E. Fletcher Co.; J. O. Kamm of the Cleveland Quarries Co.; John A. Curtis, research director of the Vermont Marble Co.; Wallace W. Key of the U.S. Bureau of Mines; F. S. Eaton, director, Research and Design Institute; and F. D. Spry of the Structural Slate Co. for critical reviews of the manuscript. Acknowledgment is made also of the helpful comments and suggestions by colleagues in the Geological Survey.

\section{THE STONE INDUSTRY}

The term "stone" is applied commercially to all natural rock materials that are quarried or mined for constructional or industrial uses. The geologist's term "rock" embraces the same materials as formational components of the earth's crust. Construction stone applies only to rock materials that are used directly for construction purposes, that is, without calcining or chemical processing, for buildings, monuments, highways, aggregate, paving, retaining walls, seawalls, and others. Shaped and finished blocks, slabs, etc., rough quarry blocks, and crushed and broken stones are embraced in construction stones.

Construction stone has a wide variety of uses, but it is convenient and practicable to classify it in two main categories, namely, crushed and broken stone and dimension stone. Production statistics for 1910-23 reported by the U.S. Geological Survey (1911-27) and for $1924-56$ by the U.S. Bureau of Mines (1927-34; 1933-58) fall within divisions of these two categories. The products of many individual quarries come under both categories. However, most crushed stone comes from quarries operated solely for that material, because many more rock formations are suitable for crushed stone than they are for dimension stone. Also, use is more localized and market values are too low to permit broad distribution. 
The relative economic importance of these two types of construction stone is demonstrated by the following statistics of production (table 1) as reported by the U.S. Bureau of Mines (1958).

The waste products of dimension-stone quarries ordinarily provide crushed and broken stone as byproducts. For geologic evaluation deposits of the two groups should be considered separately, so that, except for the following brief statements concerning crushed and broken stone, this report is concerned only with dimension stone.

TABLD 1.-Construction stone sold or used by producers in the United States, 1956

\begin{tabular}{c|r|r}
\hline \multicolumn{1}{c|}{ Material } & Quantity (short tons) & \multicolumn{1}{c}{ Value } \\
\hline Dimension stone & $\begin{array}{r}2,516,764 \\
\text { Crushed and broken stone }\end{array}$ & $\begin{array}{r}\$ 76,122,878 \\
402,012,452\end{array}$ \\
\hline
\end{tabular}

1 Includes aggregate, roadstone, railroad ballast, and riprap; does not include nonconstructional crushed stone for processing or a relatively small amount used for roofing granules (chiefly slate).

\section{CRUSHED AND BROKEN STONE}

This category includes riprap, crushed stone, and stone fragmented to various sizes for special purposes (examples: fluxes, refractories, agricultural lime, roofing granules, cement, and others). The size range of crushed and broken stone is from large blocks to finely comminuted material.

Riprap includes quarry blocks of irregular sizes and shapes, used for rough construction, such as breakwaters, jetties, piers, fills, and the like. It may be used in a rough dimension sense, in that for some purposes angularity, massiveness, and size of blocks are important, but it is not closely selected or sorted and is not shaped. It consists, in general, of the quarry wastes-broken blocks that are rejected for further shaping or sizes as dimension stone because of flaws, poor breaking qualities, or nonuniformity in texture or color. Riprap commands a low price, and has more local use than dimension stones, though the distance to which it may be transported differs in different areas according to availability of local stone. It is sold by gross weight (tons) rather than by piece or volume. Although it is a product of dimension-stone quarries it is not an economic factor in locating and developing such quarries.

Constructional crushed stone is used as concrete aggregate, road "metal," railroad ballast, road dressings, highway base (subgrade), and the like. Many dimension-stone quarries furnish crushed stone as a byproduct from quarry wastes.

Crushed and broken stones, in general, have a much more local market than do dimension stones, for they command much lower prices and cannot bear the costs of transportation to distant markets. However, economic practice in this respect varies according to avail- 
ability of stone in an area and availability of substitute materials (such as gravel, cinder, etc.). Suitable rock formations are less selective and, hence, more widespread. For some purposes, such as granules and fillers, however, some degree of selection with respect to color, chemical, and physical properties is important for crushed stone. Methods of quarrying and processing are comparatively inexpensive. Crushing and screening plants are relatively simple and, hence, quickly constructed at less cost than are plants for preparing marketable dimension stones; they may be operated intermittently to satisfy fluctuating local needs, without much financial loss for maintenance and investment. Furthermore, they require less skilled labor.

\section{DIMENSION STONE}

The term "dimension stone" is applied to natural rock materials quarried for the purpose of obtaining blocks or slabs that meet specifications as to size and shape.

The uses of dimension stone range from rough, unfinished rubble blocks of various sizes (specified, however, within a size range) for exterior walls to finely finished slabs for interior decorative finishfrom walls of rock-faced blocks to highly polished and exactly shaped and finished slabs for wainscotting and paneling. Dimension stones are subjected to restrictive and exacting specifications. First, selection is made within the quarry, so that quarrying operations are conditioned by structural and lithologic variations of the rock mass. The operations are complex in comparison with the quarrying for crushed stone. The rock is channeled and split-in some quarries it is also sawed-with considerable care. Use of explosives is kept at a minimum in order to prevent poor breakage, damage to blocks, minute fracturing, and the like. Indeed, in some quarries no explosives are used, for the modern techniques of wire sawing and channeling with a flame drill (commonly known as jet piercing), even for the hard crystalline rocks, have largely superseded the older methods for freeing large masses. The smaller quarried blocks are shaped and finished to various degrees of specifications in a specially equipped mill. The products command relatively high prices per unit and so must often compete with other construction materials.

According to their particular uses, dimension stones are chosen for such qualities as strength, durability, hardness, and ornamental features. These in turn depend upon the mineralogic composition, texture, structure, and color. In the complete evaluation of a stone deposit for specific uses quantitative physical tests and compositional analyses are involved, but it does not ordinarily devolve upon the field geologist to furnish such data. He may furnish qualitative guidance, however, based on his general knowledge of the relation of lithologic and structural features to general properties. The con- 
sulting geologist, however, may need to carry the investigations further, to involve sampling and quantitative analytical studies, thus bridging the gap between routine field geologic studies and quarrying operations.

Thus the two industries-crushed and broken stone, and dimension stone-have little in common as regards quarrying methods, preparation, use, and marketing.

\section{COMMERCIAL LITHOLOGIC CLASSIFICATION}

The petrologist's classification of rocks is much too detailed for purposes of the dimension-stone industry. The American Society for Testing Materials (1952), through its Committee on Natural Building Stones, has adopted standard definitions that are broad and yet satisfy commercial needs; furthermore they accord with standard commercial practice of many decades. (See p. 70.)

Seven principal classes of stones are recognized:

1. Granite (includes all rocks of granitoid texture and gneisses).

2. Limestone (includes dolomites).

3. Marble (includes calcitic and dolomitic marbles, onyx, travertine, serpentine, and verd antique; in general, crystalline carbonate rocks and serpentine rocks, all capable of taking a polish).

4. Sandstone (includes "bluestone," "freestone," conglomerate, and quartzite).

5. Slate.

6. Greenstone (greenish stones composed largely of chlorite, epidote, or actinolite).

7. Basalt and traprock.

Under these groups, 26 varieties are specifically defined in petrological terms.

\section{CLASSIFICATION BY USES}

Dimension stone includes blocks, sheets, and slabs in either rough or finished forms that satisfy dimensional requirements for structural, decorative, or monumental purposes. For statistical purposes dimension stones, except slate, are classified according to forms of use as follows:

Building stone

Rough construction

Cut stone, slabs, and mill blocks

Rubble

Monumental stone

Paving blocks

Curbing

Flagging 
This classification was used originally by the U.S. Geological Survey and later by the U.S. Bureau of Mines in compiling statistics on production and marketing of natural dimension stones. It does not indicate specifically the small amount of dimension stone that is used for various industrial purposes, such as paper rolls and surface plates (accurately planed plates used as bases for precision instruments), and heavy construction stone used for bridge piers, dams, and retaining walls. These materials are, however, included in the broad categories of cut stone, rough construction stone, and rubble.

Slate is reported separately because its field of use is, for the most part, distinctive, as shown by the following classification:

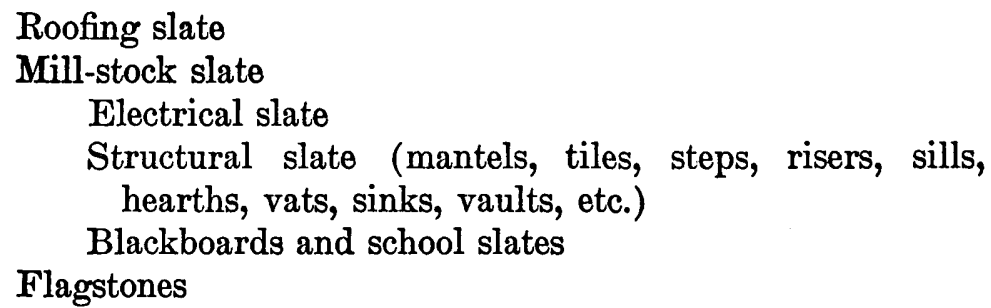

BUILDING STONE

The term "building stone" embraces a wide variety of uses in structures, including stone used for walls, foundations, sills, chimneys, trim for other materials, steps, etc., in buildings, retaining walls, bridges, seawalls, and other engineering structures. The blocks and slabs for these purposes are finished to various degrees, ranging from roughhewn, "rock-faced" (having broken surfaces) blocks to finely finished and carefully shaped slabs for interior panels and wainscotting. Preparation requires fashioning or milling of run-of-quarry blocks, with consequent selection of material and rejection of waste blocks and culls.

Strictly speaking, no sharp discrimination can be made between building stones and monumental or ornamental stones, for structural blocks and slabs, though chosen primarily for durability and soundness, often are chosen also for their ornamental value, either as to color or type of finish. Moreover, monuments range from simple markers to ornamental structures that are essentially buildings. Thus the same quarry may produce stone that, by selection, will be used for building, ornamental, or monumental purposes.

The categories of building stone given on page 7 are necessarily generalized and do not permit close discrimination of products, for terminology is not consistent within the industry, as noted below.

According to Bowles (1917, p. 23-25) four principal forms of stone are used for walls, namely cut or finished stone, ashlar, rough building stone, and rubble. Cut or finished stone consists of blocks shaped and sized accurately and uniformly, except for corners, door 
and window spaces, caps, and cornices for which the blocks are carefully carved or shaped to requirements. Moreover they are surface tooled. Ashlar blocks are rectangular, generally small, and have rock-faced, sawed, or planed surfaces. Ashlar is laid in courses. which may be even, that is, of uniform height (but in which blocks. may not be of uniform length) for each course; succeeding courses, however, may differ in thickness. Random ashlar consists of blocks. of several sizes that may be fitted together. Rough building stone consists of rock-faced blocks of various shapes and sizes. Rubble is generally applied to irregular blocks having one good face and is the cheapest form of building stone.

Recently, small, thin veneer slabs that simulate the appearance of ashlar and rubble walls have come into common use. In the ashlartype veneer both coursed and random rectangular faces are used; in the rubble type the exposed faces are polygonal but are not sized or accurately shaped, giving what is known as spider web veneer. Both ashlar and rubble veneer blocks are, of course, prepared to specified thicknesses, usually less than 3 inches. Seam-face stone and prominently colored stones appear to have particular favor as veneer blocks of these types. Thus, some quarries may readily lend themselves to such products, but be unsuitable for the larger and thicker or accurately shaped veneer panels, depending on the spacing and orientations of natural fractures.

Baker (1914, p. 279-281) includes in ashlar all squared blocks with various finishes and with smoothly dressed joints, and differentiates three types-range, broken range, and random. He stipulates further that setting joints are one-half inch or less and uniform in thickness. He includes in rubble masonry all unsquared or roughly squared stones, which may be either uncoursed or coursed ("levelled off at specific heights to an approximately horizontal surface"). Also, for rubble, "It may be specified that the stone shall be roughly shaped with the hammer, so as to fit approximately." Ashlar masonry, then, is the best grade of stone masonry, and rubble is the lowest.

As the subject is reviewed, it appears that the terminology has become somewhat confused and hence inexact, with differing usage among producers. For the most part confusion arises in use of the terms "ashlar" and "rubble." Some apply the term "ashlar" to completely squared blocks, others include blocks with two parallel faces but unsquared ends, but all ashlar lends itself to laying in courses. The British Standards Institution (1957) defines ashlar as "masonry consisting of plain blocks of stone, finely dressed to given dimensions and laid in courses." Use of the term "rubble" is even more confused, ranging from unsquared blocks with one good face to roughly squared blocks of various sizes. The British Standards Institution 
defines rubble as "stone of irregular shape and size" and recognizes random rubble ("irregular unsquared stone" not in courses) and coursed rubble ("rough squared stone" in courses).

For statistical purposes the U.S. Bureau of Mines recognizes the classification by Bowles (1917), given above. It is clear, however, that standardization of terms is needed.

\section{MONUMENTAL STONE}

Stone that is marketed as monumental stone must satisfy more exacting requirements, than even the highest grades of cut and fashioned building stone. In general, uniformity in texture and color, freedom from flaws, and suitability for polishing and carving are the principal prerequisites. For some monumental stones, variations in color and texture are desirable, providing the stone is sound. Furthermore a strong contrast is usually desired between polished and unpolished areas so that lettering or designs may appear prominently. Some quarries, and even some districts, are known primarily as producers of monumental stone, though they may contribute to a small extent to the building stone market. For example, the Barre granite from Vermont, has been marketed almost exclusively as monumental granite, though it is used locally for building purposes. A higher price market determines the diversion of such stone to monumental rather than constructional use. On the other hand, stones from some districts fall into both categories. The Quincy granite from Massachusetts, for example, has been marketed broadly for both uses.

Stone quarried primarily for the monumental market is subjected to very careful selection in both quarry and mill. This results in rejection of a large percentage of the quarry product as waste. The grout piles of the Barre granite in the Barre-Williamstown district, Vermont, are impressively large compared with those in districts that are worked for building stones; in this district, according to reports, approximately 85 percent of the quarried material is rejected as monumental stone, but much of this is sound and suitable for building purposes. A highly competitive market, technological exactions, and transportation differentials to ready markets, rather than its inappropriateness for general construction uses, may determine the restriction of a stone to a monumental destiny.

Actually, of course, the choice of a stone for monuments is, in part, a matter of architectural preference, for in some monumental structures the higher quality building stones may be used to achieve a desired decorative effect. Nevertheless, carving generally demands uniform and fine-grained textures, and high polish imposes compositional as well as structural and textural limitations. The fine- and medium-grained granites and marbles furnish most of the monu- 
mental stones. Only granites and marbles have been reported in production statistics of monumental stone in recent years.

Statuary stones constitute a special variety of monumental stone adapted to delicate carving. For this purpose is desired stone that is uniformly fine textured, tightly knit, easily worked, not easily chipped, and without foliation or prominent bedding planes. Marble is pre-eminent in supplying statuary stone, though fine-grained monumental granite is also used. Statuary marble is defined by Merrill (1903, p. 337) as "a pure white saccharoidal stone suitable for the purposes of the sculptor." Bowles (1934, p. 178) describes statuary marble as "pure white, uniform, and usually fine-grained in texture, and somewhat translucent, and must have marked adaptability for carving."

\section{ORNAMENTAL STONE}

A distinction should be made between monumental and ornamental stones. Some stones used for ornamental purposes would not satisfy the requirements for carving, yet because of certain distinctive qualities-such as markings and color-they may command high prices. Most ornamental stones are used for interior finishes but some are used for polished exterior panels. Many ornamental stones are imported. Furthermore, for reporting production statistics ornamental stones are included, in part, in the category of building stones rather than monumental stones.

A stone deposit can rarely be judged for ornamental purposes, for the properties upon which depend architectural or decorative choice cannot be determined easily. In areas where quarries have produced and marketed decorative stones the geologist may suggest close similarities between stone in developed and undeveloped properties. It is more often possible to discriminate between potential building and monumental stones. His task as a geologist is generally fulfilled, however, by carefully recording the extent, and the more general geologic and lithologic properties, of the deposit, that is, texture, structure, uniformity, color; homogeneity, and composition.

\section{CURBING}

Production of long slabs for edging roadways and sidewalks comprises an important part of the stone industry in some parts of the country. In 1956 production of curbing was reported for but 12 States, 8 of which are east of the Appalachians and in which resources of suitable stone are particularly abundant. After a marked decline during the World War II period the production has maintained a fairly constant level at nearly 1 million linear feet; in valuation it comprises slightly more than 5 percent of the dimensionstone industry. 
Stone curbing competes with manufactured materials, chiefly concrete, but the superior resistance of hard stones, particularly granite and quartzite, to abrasion and weathering has maintained the industry for those areas where supplies are. economically available and use has been long continued. The use of natural stone for curbing in place of inferior materials might well be considered for other areas where suitable undeveloped deposits are known to occur.

Relatively thin and short slabs are also used to face bordering slopes of highways ("slope curbing"). Slope curbings are favored by many highway engineers because of their superior durability and ease of emplacement over artificial materials that require construction of forms for molding and setting. For production of both slope and vertical curbing, a stone should possess an easy rift (cleavage) so that straight and fairly smooth faces may be obtained with a minimum of working.

Granites, sandstones, and quartzites are the chief stones used for curbing, and granites furnish more than 90 percent of the market. Medium-grained granite is used most commonly, but both fine- and coarse-grained granites are suitable if easily worked. Coarse-grained granites are commonly less favorable than others because of more difficult material cleavages and greater unevenness of the split faces, but this is not a completely consistent relationship between cleavage and texture, for some of the coarser textured granites-particularly gneissic varieties-have furnished satisfactory curbings. Thin and fine-grained aplite dikes and quartz veins are less objectionable in curbings than in other kinds of dimension stones, though in quarrying the stone may split along these structures.

\section{FLAGGING (EXCEPT SLATE)}

Flagging (flagstone) consists of thin slabs used for walks, driveways, and paved areas such as courtyards, carports, patios, and the like. Most flagstones are composed of fine-grained sandstone, siltstone, or slate, but some limestone flagging is produced. Granite and marble, because of their interlocking crystalline textures and lack of easy fissility are generally less suitable, although some of the finer grained granites that have an easy rift permit the splitting of fairly thin slabs.

In general stones that permit easy splitting into thin slabs of uniform thickness are most suitable for flagging, although sawn slabs are used to some extent. By far the greater part of the production comes from fine-textured argillaceous sandstones and siltstones in which the bedding planes are even and the beds are thin. Markedly crossbedded sandstone, however, may be unfavorable for natural splitting because of its variable and irregular bedding cleavage, but may be sawn. 
Very compact uniformly dense and thin-bedded limestones have. been used successfully for flagging, particularly in the Central States; such stones should have very low porosity and be free of shaly or otherwise soft and porous partings.

Flagstone slabs are commonly 2-3 inches thick; thinner slabs are apt to be weak toward transverse stresses, though thinner slabs of some bluestones and slates, are satisfactory for walks and pavements: not subjected to heavy loads. Bluestone is a variety defined by the American Society for Testing Materials (see p. 73) as a dense, hard, indurated fine-grained sandstone that splits easily into thin, smooth slabs. It is commonly dark or slate gray, but the term is applied to all varieties irrespective of color.

Statistics for 1956 show that, in volume, sandstone (chiefly bluestone) constituted about 65 percent of the flagging produced, limestone about 30 percent, and others (chiefly argillites) about 5 percent.

\section{PAVING BLOCKS}

Paving blocks are small rectangular blocks used for roads, docks, freight yards, and any other areas subjected to heavy and abrasive commercial traffic. They are also used sometimes as base courses for heavy-trafficked highways, where they are surfaced with cement. On heavy-trafficked slopes, they have afforded a foundation that resists creep and buckling. The substitution of rubber-tired motor vehicles for steel-tired horse-drawn trucks has probably been the greatest factor in the substitution of asphalt, concrete, and cement pavements for paving blocks. Indeed, the paving-block industry has all but disappeared; in the early 1920's the annual production was. more than 40 million blocks. A sharp downward trend began about 1927 , and by 1954 production had declined to 208,000 . In 1955 , however, production jumped to over 1 million blocks in response to a sudden demand. There is some market for small nearly cubical blocks for bordering streetcar rails, center strips of highways, and minor architectural and landscaping purposes, such as patios, borders, and the like.

Like curbing, hard medium- to coarse-grained stone with easy rift (easiest cleavage) and grain (second easiest cleavage) is required for paving blocks. For this reason medium-grained granite is most adaptable, if it may be split and cobbed readily along rift and grain directions. In places some quartzites have been used, but this stone is ordinarily more difficult to shape than granite.

\section{ROOFING SLATE}

Originally the principal use of slate was for thin roofing shingles. This use has declined greatly in favor of other roofing shingles, in 527187-60-2 
part made of slate granules attached to an asphalt-type base. From a maximum of $\$ 5,186,167$ in 1908 , the reported production value of roofing slate has declined to $\$ 2,588,971$ (1956). The valuable qualities of this roofing material are its durability and fireproof nature; relative cost and weight are its chief detractions. It still maintains some favor because of its architectural adaptability and attractiveness, as well as its outstanding durability.

Roofing slates generally range in size from 7 by 9 inches to 16 by 24 inches, and $1 / 8$ to $1 / 4$ inch in thickness. Needless to say the stone must possess smooth, straight, and easy cleavage, without nodules, "knots," or bands of foreign minerals.

\section{MILL-STOCK SLATE}

Mill stock includes blocks and slabs suitable for fashioning into structural units, slabs and plates for electrical purposes, blackboards, and the like. (See "Classification by uses," p. 8.) According to Bowles (1955), "A soft, even-grained slate, preferably not highly fissile, is required for such purposes." Electrical slate requires, in addition, strength and very low electrical conductivity; furthermore, it must be easily workable by cutting and drilling without chipping.

\section{FLAGGING SIATE}

Slate used for flagging is less restricted as to physical properties than is that suitable for other dimensional purposes. Quarry blocks and slabs discarded from mill stock and roofing stock are commonly adaptable.

\section{ECONOMIC ASPECTS OF THE DIMENSION-STONE INDUSTRY}

A brief review of production statistics will help to orient the field geologist with respect to the importance of dimension stones as mineral resources.

The total mineral production (except fuels) of the United States in 1956 was valued at $\$ 5,772$ million. Of this amount, nonmetallic production (which includes stone) was valued at $\$ 3,415$ million. The total value for the stone industry was $\$ 765,342,321$. The value of all varieties of dimension stones amounted to $\$ 82,924,914$ or 2.4 percent of the nonmetallic mineral production.

\section{DIMENSION STONE (EXCEPT SLATE)}

The accompanying graph (fig. 1) shows the value and quantity (since 1916) of dimension stones, except slate, produced from 1910 to 1956 , inclusive. It is clear that, in large part, both curves follow the same general trend and reflect the periods of business expansion and recession. They show wartime declines due to diversion of in- 


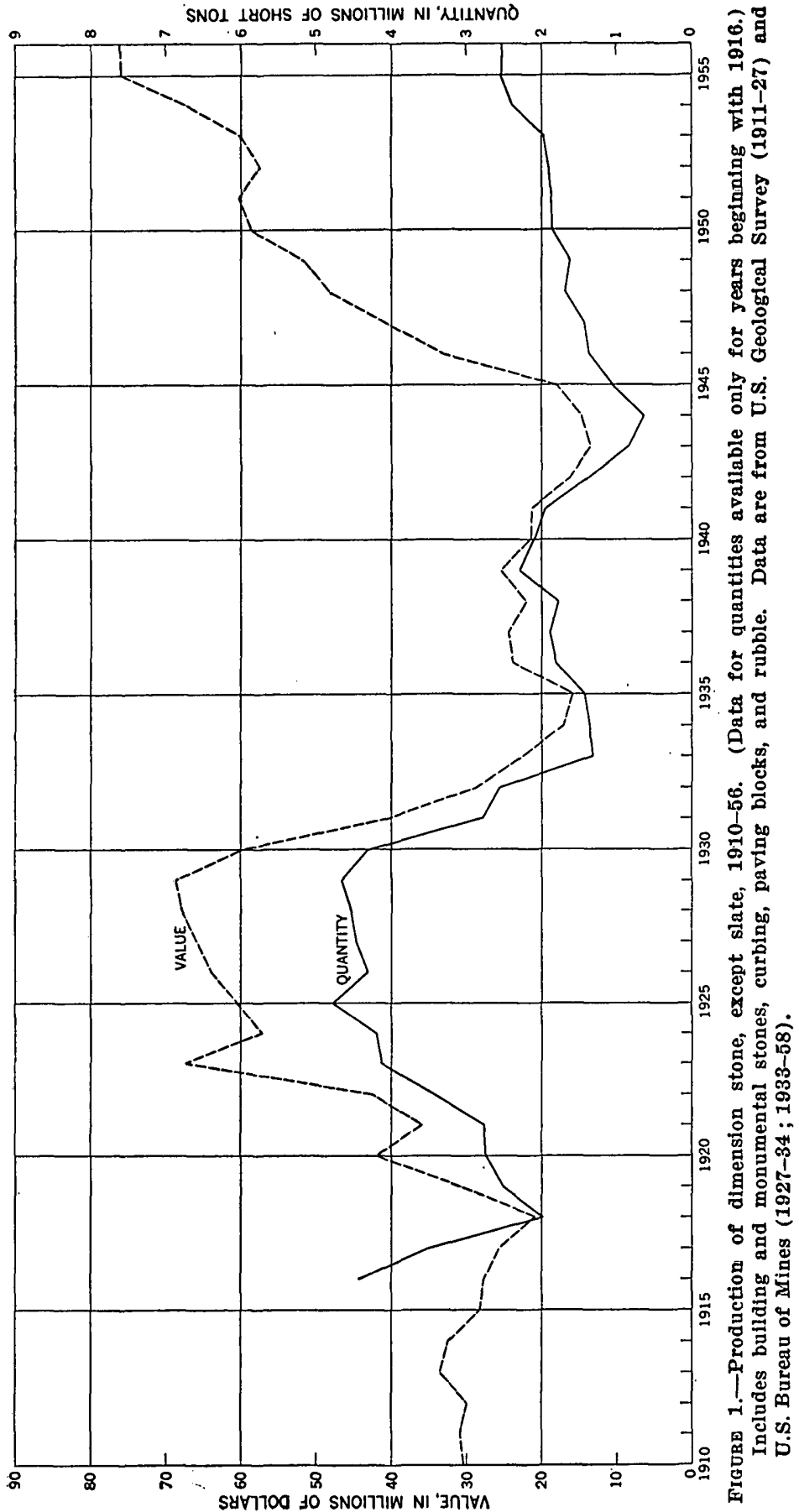


dustrial activities from nonstrategic construction and postwar expansion due to renewed construction activities. It is particularly noteworthy, however, that a general lower quantity level has been maintained consistently from the early 1930's, although the curve showing value has risen in recent years to nearly an alltime peak. The divergence of these curves is more marked than in earlier periods and represents higher prices per unit as a result of higher costs of quarrying, milling, and marketing.

The quantity curve reached its lowest point of the last 50 years in 1944, near the end of World War II. This level was even below the low point in 1918 at the end of World War I. The recovery since World War II has not been comparable in quantity to that following World War I; the general level, indeed, seems to approximate the high level of 1924-30. Though rising slowly to 1955, the quantity curve apparently tends to level off at slightly more than half of the 1925 peak, despite the great expansion of the building industry in the last decade or so. Of this, the use of dimension stones as exterior walls of large buildings is doubtless subordinate to combined uses of other materials.

The following production statistics indicate the relative industrial importance of each reported type of dimension stone, except slate, for 1956. According to these data, building stone (all classes) amounted to approximately 69 percent in value or 81 percent by weight, and monumental stone approximately 24 percent in value or 9 percent by weight, of all dimension stone (U.S. Bureau of Mines, 1958).

TABLE 2.-Dimension stone sold or used by producers in the United States, 1956

\begin{tabular}{|c|c|c|c|c|c|}
\hline Material & $\begin{array}{l}\text { Short tons } \\
\text { (approx.) }\end{array}$ & $\begin{array}{l}\text { Percent of } \\
\text { total quan- } \\
\text { tity }\end{array}$ & Cubic feet & Value & $\begin{array}{l}\text { Percent of } \\
\text { total value }\end{array}$ \\
\hline $\begin{array}{l}\text { Building stone: } \\
\quad \text { Rough construction } \\
\text { Cut stone, slabs, mill blocks } \\
\text { Rubble..... } \\
\text { Monumental stone } \\
\text { Paving blocks. } \\
\text { Curbing } \\
\text { Flagging }\end{array}$ & $\begin{array}{r}321,866 \\
1,256,831 \\
469,711 \\
234,748 \\
6,004 \\
120,577 \\
107,027\end{array}$ & $\begin{array}{r}12.8 \\
49.9 \\
18.7 \\
9.3 \\
.2 \\
4.8 \\
4.3\end{array}$ & $\begin{array}{r}16,499,633 \\
2,832,989 \\
1988,309 \\
1,462,437 \\
1,353,690\end{array}$ & $\begin{array}{r}\$ 3,227,845 \\
47,557,383 \\
1,587,588 \\
18,016,136 \\
88,361 \\
3,550,481 \\
2,095,084\end{array}$ & $\begin{array}{r}4.1 \\
62.5 \\
2.1 \\
23.7 \\
.1 \\
4.7 \\
2.8\end{array}$ \\
\hline Total & $2,516,764$ & 100.0 & & $76,122,878$ & 100.0 \\
\hline
\end{tabular}

1 Number of blocks.

Finished building stone (cut stone, slabs, and mill blocks) comprised approximately 91 percent in value or 61 percent by weight of total building stone, and approximately 62 percent in value or 50 percent by weight of the dimension-stone industry. Less than 8 percent in value or 9.3 percent by weight of the dimension-stone production is recorded for curbing, flagging, and paving block. 
These figures may be considered as probably representing the general levels of immediately succeeding years. The market for dimension stone appears to be more dependent upon the construction of nonresidential buildings than upon other uses.

The decline in quantity production of building stone is not, however, a true measure of the overall continued use of stone in building construction. To a considerable degree the lower levels of production since 1930 are due to changes in construction practice for large buildings. It is true, of course, that manufactured materials (steel, cement, ceramics, etc.) have been increasingly substituted for stone. Nevertheless, natural stones are of broad and general use, constitute a useful and easily accessible natural resource, possess durability and strength, and are architecturally distinctive. They have certain disadvantages in fashioning to specified shapes and sizes, and for many structural purposes are at an economic disadvantage with respect to manufactured materials that can be cast or molded. One of these disadvantages is the greater cost of hand labor in fashioning stone over the molding of manufactured materials. On the other hand, for much building construction, appropriately selected stone has no adequate architectural substitute among currently used artificial products.

Formerly, massive blocks of stone were the chief material used for large buildings. Walls were thick, without reinforcement by other materials, and the blocks were carefully shaped, fitted, and mortared to bear the entire weight and stresses of the structure. Present practice in the larger buildings is to use stone chiefly as veneer slabs and thin panels, fixed and keyed upon a basic framework of steel and concrete. Indeed a very recent development has been the use of stone as "curtain walls"-consisting essentially of thin slabs attached to a framework but without massive backings. Whether or not curtain-wall construction will ultimately prove to be durable remains to be demonstrated. Thus the volume of stone used for a building of a given size is reduced to a small percentage of that formerly required when walls were built of solid masonry. This practice has had the further effect of requiring stone producers to fashion the product to meet more complicated specifications as to. sizes and shapes. Many producers have found it necessary to maintain engineering and architectural staffs, not only to control fabrication but also to advise architects and construction engineers. More elaborate milling plants are maintained by the producers. By the same token, many small quarry operators have not been able to compete. Quarry operations are now more systematized, with new and more complicated methods of extraction. The initial investment in both the quarry and plant must be much greater than formerly. Competition requires closer control on production costs through tech- 
nical organization. Economy must be effected in part through largescale operations.

Practically all stone districts operated in the first 25 years of this century now have many abandoned small quarries. Only a very few of these will ever be reactivated; they remain as symbols of an industry that was far more penetrative into the lives of many communities than is true today. For the geologist, however, they furnish economic, lithologic, and structural data that would not be revealed by examination of natural outcrops. Moreover, operators often seek areas for expansion or possible sources of particular type of stone to meet a current demand. For them detailed descriptions of abandoned quarries within their operating districts or elsewhere are valuable aids to prospecting.

Although comparatively few of the older quarries have sustained production through the past 50 years, some of these now undoubtedly produce more stone per year than formerly, despite the overall volume decline of the industry. This condition bespeaks technologic and economic changes in methods of production and marketing.

\section{DIMEANSION SLATE}

Table 3 shows production of dimension slate for 1956 (U.S. Bureau of Mines, 1958).

TABLE 3.-Production of dimension slate sold by producers in the United States, 1956

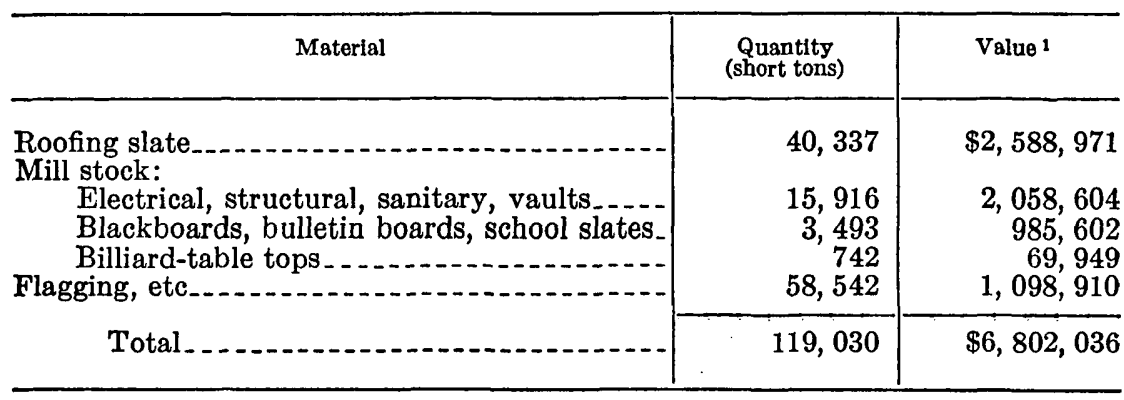

1 Sold by producers.

Figure 2 shows yearly values beginning with 1910 and quantities beginning with 1919 of dimension slate sold or used by producers in the United States. In general, the curve is closely similar to that for other dimension stones (fig. 1) following broadly the general economic levels of both war and postwar periods, and the intervening recession period of the 1930's. However, for the period 1919-29, the percent rise in quantity for dimension slate was only about one-fifth that for other dimension stones, and the percent rise for the period 1944-55 was less than half that for other stones. It appears that the dimension-slate industry has been more greatly affected by substitution of other materials than has other dimension stone. In particular 


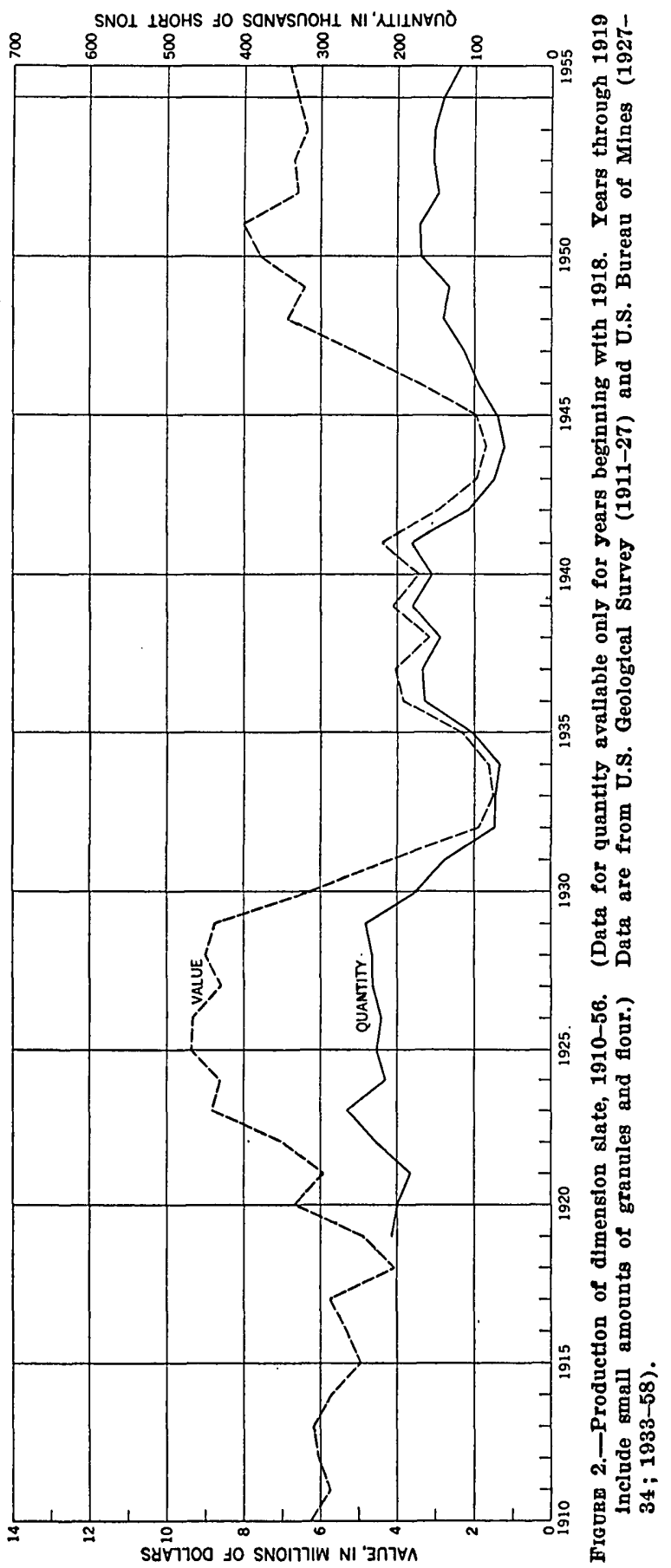


it appears that production of roofing slates began to be seriously affected as early as 1917 by the increasing use of slate and other rock granules for asphalt-base roofing, a technical development that started about 1910. Mill-stock slate also suffered a quantity deterioration relative to other dimension stones during the same periods, though its percent recovery since 1944 has been much greater than roofing slate. The percentage increases during these two periods of expansion, that is, 1919-29 and 1944-55, for dimension stone (except slate), dimension slate, roofing slate, and mill-stock slate are indicated in table 4.

TABLE 4.-Percentage increases in production of dimension stone in the United States 1919-29 and 1944-55

\begin{tabular}{|c|c|c|}
\hline Material & $1919-29$ & $1944-55$ \\
\hline $\begin{array}{l}\text { Dimension stone (except slate) } \\
\text { Dimension slate (total) } \\
\quad \text { Roofing slate } \\
\quad \text { Mill-stock slate }\end{array}$ & $\begin{array}{l}79 \\
16.4 \\
15.7 \\
8.0\end{array}$ & $\begin{array}{r}294 \\
131 \\
39.2 \\
66.7\end{array}$ \\
\hline
\end{tabular}

\section{GEOGRAPHIC DISTRIBUTION OF DIMENSION-STONE DEPOSITS}

The style of a national architecture may evidently depend, in large measure, upon the nature of the rocks of a country. (John Ruskin)

Rock formations of one kind or another that are suitable for use as dimension stones are almost ubiquitous. Some large areas are, indeed, devoid of formations that will yield blocks for major construction, such as large buildings, bridges, retaining walls, or for monumental use; some areas even lack stone for foundations of houses. Into these areas dimension stones must be imported. But for the most part some type of dimension stone is available within reasonable distances, though the choice may be greatly restricted.

The distribution of the various rock types reflects, of course, the distinctive geologic history of the regions in which they occur. From the "Geologic Map of the United States" (U.S. Geol. Survey, 1932), it is possible to prognosticate broadly the kinds of stones that may or may not be found in an area. State geologic maps will provide more detailed information. By the same token quadrangle geologic maps, being of still larger scale-usually 1 mile to the inch or largershould provide data adequate for local prospecting that is basic for industrial appraisal. This, indeed, should be one of the objectives of such mapping.

Well-trained geologists are aware of the general facts of distribution and can interpret from the "Geologic Map of the United States" or from the State geologic maps the areas in which the principal types of stone may or may not be found. This ability is not of common knowledge to laymen. 
Classes of commercial stones fall readily into two broad groups of rocks as regards their genesis and geographic distribution-crystalline rocks (whether of igneous or metamorphic origin) and noncrystalline rocks (of sedimentary origin). Commercial granites, basalts, greenstones, marbles, quartzites, and slates comprise the crystalline rocks; sandstones, conglomerates, and limestones (including dolomites) compose the sedimentary rocks. Standard commercial definitions of these classes are given on pages 71 to 74 . Technically, the crystalline metamorphic rocks include the gneisses, schists, marbles, quartzites, and slates; however, a few marbles and quartzites are found in sedimentary areas, where limestones and sandstones have been sufficiently recrystallized to afford these commercial types, although rocks of the regions in which they occur have not undergone general metamorphism in the geologic sense. Also, areas of true metamorphic rocks are usually coincident with areas of igneous rocks, although the converse is not true.

It is not feasibly within the scope of this report to indicate details of distribution for the major classes of stone. However, it may be of some interest to indicate the lithologic provinces of the country as related to occurrences of the two major types, as defined above. To that end the map (pl. 1) has been prepared, based on the "Geologic Map of the United States." The map indicates also the States that reported production in 1956 of the principal classes of dimension stone, except basalt (trap) and greenstone. Basaltic rocks are of widespread distribution in areas of both crystalline and sedimentary rocks; greenstones are generally confined to areas of metamorphic rocks.

Theoretically, at least, it should be possible to find all crystalline varieties of stone in a regional crystalline-rock area such as the New England-Appalachian province (province 2; see below). Local areas within a province, however, will be devoid of some types, depending upon differences in geologic history. Considering New England, as an example, one finds the granitic rocks widely distributed, except for the northern parts of Maine (for which, however, detailed geologic data are scant) and New Hampshire, and the great Vermont-Berkshire Valley, that is, the belt west of the Green Mountains axis.

On the other hand, marbles are abundant and widely distributed along the Vermont-Berkshire Valley area but are relatively scant or wanting elsewhere in New England, where granitic rocks are abundant. These marbles were originally calcareous sediments and have, for the most part, been metamorphosed and metasomatosed to a comparatively high degree, that is, beyond a stage of simple recrystallization that characterizes marbles. This reflects the different 
degrees of susceptibility to metamorphism of carbonate and siliceous rocks. Thus there is little chance of reward in prospecting for large masses of commercial marble in New England east of the Green Mountains, though even here small bodies of marble occur and have been exploited for purposes other than use as dimension stone.

It is somewhat more than simply fortuitous, then, that production of dimension marbles has been restricted mostly to a few areas in the New England-Appalachian crystalline belt. These are the VermontBerkshire Valley in western New England, northeastern Maryland, north-central Georgia and adjacent part of North Carolina, eastern Tennessee, and east-central Alabama. Nevertheless, although a general separation is apparent, local areas elsewhere of granitic rocks or of marbles, as the Yule marble (formerly called Yule limestone) of Gunnison County, Colo., cannot necessarily be considered mutually exclusive of each other.

In similar fashion analysis might be made of other major crystalline provinces.

It is noteworthy that from six States-North Dakota, Idaho, Rhode Island, West Virginia, Mississippi, and Louisiana-no production of dimension stone was reported in 1956; of these, all except Louisiana and Mississippi have reported some production in past years.

Province 1.-Province 1, the Atlantic and Gulf Coastal Plains, affords few consolidated formations that yield usable stone. Except for the very porous shell limestone (coquina) of Florida, only the inner portion (Cretaceous rocks) has provided any dimension stone; a small production of limestone has been reported from Cretaceous rocks in east-central Texas (Williamson County) and in central Georgia, and of sandstone from eastern Virginia.

Province 2.-Province 2, the eastern crystalline belt, includes the eastern Appalachians, Piedmont belt, Adirondacks, and New England; it is characterized geologically by a wide variety of metamorphic and igneous rocks. Each State of this belt except Delaware has contributed in the past to production of granitic rocks, marble, or slate. In the course of time this province has accounted for probably more than 90 percent of the country's production of these dimension stones; for 1956, it is estimated that it has furnished 75 percent or more of the commercial granites and 85 percent or more of the commercial marbles and slates. Of the commercial granites, Massachusetts and Georgia each produced about 23 percent and Pennsylvania produced more than half of the dimension slate. Tennessee led in the production of marble with nearly 47 percent. Thus, the relative importance and dominance of the province in the production of the crystalline stones is indicated. This is, however, in no sense a relative measure of potential resources for the several crystalline areas of the country; rather, it reflects the development 
history of the stone industry which, in turn, reflects the localization with respect to principal market regions.

The northern Maine area (2a, pl. 1) is chiefly one of Paleozoic sedimentary formations into which igneous rocks have been intruded in several places. Little detailed geologic mapping has been done in this area so that its possible resources of either crystalline or sedimentary rocks suitable for dimension stone cannot be evaluated. The area is very sparsely populated and so lacks development of industries and transportation; these conditions are unfavorable, of course, for establishment of a stone industry.

Triassic sandstone areas $(2 \mathrm{~b}, \mathrm{pl} .1)$ that lie within province 2 are worthy of note, for they furnished the famous "brownstones" (Connecticut Valley, Mass., and Hummelstown, Pa.), and the Seneca Red sandstone, of former usage, of central Maryland, that were popular in the latter part of the 19th century and in the early 1900's. Present (1956) production of these stones is very small and intermittent.

Province 3.-Province 3 comprises an extensive area of Paleozoic and Mesozoic sedimentary rocks of the Great Plains, central interior, western Appalachians, Appalachian (Cumberland and Allegheny) Plateaus, and the Valley and Ridge (Great Valley) physiographic province. This is a region in which crystalline rocks are entirely wanting, except for small scattered areas in Montana, South Dakota, Oklahoma, and Missouri, in some of which commercial granites have been quarried. In this province are abundant and widespread deposits of sandstone and limestone (including dolomites).

According to 1956 statistics, production of dimension sandstone was reported from 27 States, 19 of which are in this province and which accounted for nearly 95 percent of the total production. About 76 percent came from 5 States, as follows (percentages approximate): Ohio, 25 percent; Colorado, 20 percent; Pennsylvania, 16 percent; Tennessee, 9 percent; New York, 6 percent. However, practically all the reported New York, and a considerable part of the Pennsylvania production consists of bluestone used chiefly for flagging and curbing. The Colorado and Tennessee production comprise thin-bedded fine- to medium-grained quartzitic sandstones that lend themselves particularly to use as ashlar blocks, veneer or panel slabs, flagging, floor tiles, and steps; the beds range up to 15 inches (mostly less than 12 inches) in thickness. Excluding the bluestones of New York and Pennsylvania, Colorado ranked second and Tennessee ranked third in production of dimension sandstone in 1956.

Of the 22 States that reported production of dimension limestone in 1956, 16 lie within this province and accounted for 85 percent of the country's production. The Bedford-Bloomington district, Indiana, contributed approximately 65 percent of the country's out- 
put; this district has for many years been the chief producing area. The "Bedford oolitic limestone" is part of the Salem limestone of Mississippian age, which has widespread distribution in Indiana and adjacent States, and has, at times, been quarried in Kentucky ("Bowling Green oolitic limestone"). Other notable commercial dimension limestones of the province that have been quarried intermittently are the Niagara limestone (dolomitic) of northern Illinois and southern Wisconsin, the Burlington limestone of western Illinois and adjacent States, and dolomitic limestone near Kasota and Mankato, Minn. However, limestones suitable for uses as dimension stone are of widespread occurrence throughout the province. A crystalline limestone that takes sufficient polish to be classed as commercial marble is quarried in Jasper County (Carthage district) in southwestern Missouri.

Within province 3 are several small areas of crystalline rocks; these are potential sources of commercial granites, but most of them have not been exploited because of remoteness from areas of use. An area in southeast Missouri (Iron County) has produced a monumental granite, known as Missouri Red, a small amount of building stone, and, at times, paving blocks; another area in southwest Oklahoma has also produced monumental granite and some building stone. Both of these areas reported production in 1956.

Province 4.-Province 4, the Lake Superior area, comprises most of Minnesota, northern Wisconsin, and northwestern Michigan, in which crystalline rocks are abundant and widespread. Minnesota and Wisconsin have long been important producers of dimension granite -both monumental and building, the area ranking second to province 2. The granites of province 4 present a considerable variety in both texture and color. Many of them are various shades of red, gray, and blue gray. Some "black granites" (gabbro) are also exploited, and in at least one area, a dense textured volcanic rock, rhyolite, is quarried. According to 1956 statistics, Minnesota ranks fourth in the production of dimension granite, accounting for approximately 10 percent of the country's production; it is estimated that the province produces between 15 and 20 percent of the total production.

Province 5.-Province 5, the Cordilleran, Great Basin, and Pacific coastal belt, comprises a large area in which both crystalline and sedimentary rocks are abundant and widespread. Because of the complexities of distribution, the province does not lend itself to a practicable brief separation of rock types. Ten of the eleven States of this province reported production of dimension stones in 1956, the nonproducing State being Idaho. Granites were reported from 5 States of the province, sandstones from 6 States, limestones from 2, slate from 1 (California), and marble from 1 (Colorado). It is 
estimated that less than 7 percent of the country's production of dimension stones can be credited to this province; Colorado accounted for approximately $41 / 2$ percent, and Arizona and California for less than 1 percent each.

The low production of dimension stones in province 5 is not, however, in any way a measure of available resources of dimension stones in the area, nor is the fact that the production is almost entirely from three States significant of the distribution of rock formations suitable for use as dimension stones. Resources of suitable formations are practically boundless and broadly distributed, but economic conditions, including sparseness of population and lack of industrial development over most of the area, have not been favorable for widespread development of the stone industry. Much dependence has been placed upon importation of dimension stones from other parts of the country for the larger buildings and structures in the principal urban areas of the province.

\section{INDUSTRIAL FACTORS IN EVALUATION OF DEPOSITS}

The evaluation of deposits of dimension stones is faced with a variety of conditions, some of which are peculiar to the economy of the stone industry. For one thing, utilization of stone is, in general, more localized than is true of other geologic materials, such as metallic ores and the majority of industrial minerals. This is more true of construction than of monumental stones. Nevertheless, even for monumental stones a considerable part of the market is relatively provincial. High costs of transportation per unit tend to increase competition with local products. Also the competitive aspect of the industry is particularly strong, not only between natural stones and artificial-stone products, but also among the various commercial classes of stones, and even among stones of the same class. This is, in part, offset by architectural or esthetic preferences.

It is true, of course, that some decorative and monumental stones find a wide, even international, market, so that the comparatively local aspect of the industry should not be overemphasized. These widespread uses derive mostly from distinctive decorative qualities, especially when used for interior finishes, rather than from superior physical or chemical properties. Many areas can supply as excellent stones as those already in production, but exploitation demands the existence of a ready market, while, at the same time the architectural and constructional merits of stones from long-established districts are generally well known and need no trial to prove their virtues. Moreover, the present practice of using comparatively thin, highly finished, and exactly fashioned veneer slabs for the larger buildings should favor much broader markets than formerly. For such products, transportation costs bear a lower overall ratio to total costs 
than is true of massive blocks formerly used as the principal construction material.

Other strong factors in the continued successful exploitation of stone deposits are operational organization and marketing skill, productive capacity of a plant, ability to deliver large quantities of uniform material within a given time, and means for dressing and fashioning stone to specifications of dimensions and finishes. Thus the long-established, operating quarry using modern methods of extraction and milling has a strong initial advantage over undeveloped resources of equally high quality stones that may be much nearer the point of use.

The countless abandoned quarries in nearly all the long- and wellestablished districts give testimony to the above economic and industrial facets. As pointed out, however, the fact that so many of the one-time successful quarries have been abandoned does not signify that the stone industry is in a decline toward extinction, for statistics of production through the past several decades indicate a new level of stability. The change is, rather, a reflection of the evolution in industrial and engineering economy, for advances in techniques of construction have changed modes of use in large structures, while costs of production have been tempered by improved techniques in quarrying and finishing, made possible mostly through large-scale production.

\section{Chemical PROpertes}

Many users of dimension stones, especially of stones used for buildings and monuments, request chemical analyses of samples submitted. Except to meet very special conditions of use, such as stones subjected to unusual chemical or heat conditions, the ultimate chemical analysis has very little value in the first, broad appraisal of a dimension stone. The trained geologist can estimate closely enough the probable composition from a lithologic or petrographic examination of the stone. If appreciable quantities of minor deleterious minerals occur in the stone, partial chemical analyses can well be advised, but it is not ordinarily the function of the field geologist to have such analyses made, or to do sampling necessary for the purpose.

Stones for exterior use should, of course, be resistant to the chemical weathering effects of their environments. Calcareous rocks, including sandstones with calcareous cement, are particularly susceptible to smoke and other industrial fumes that contain sulfurous acids and to some ground and soil waters. Actually, however, this need not concern the field geologist, as his appraisal of a stone is qualitative and is based on ordinary uses and environments and natural weathering effects as seen in outcrops. Appreciable amounts of pyrite or other easily oxidizable minerals should be noted, because of their deleterious effects even under the slow attack of normal 
weathering processes. But by and large the general report of the field geologist need not involve ultimate chemical analyses and the involved sampling that such analyses require. To obtain adequate samples for chemical analyses that are representative of the deposit as a whole is a difficult and complicated procedure, involves considerable expense and time, and is not commensurate with the practical value of the analyses. For purposes of geologic field study, therefore, mineralogic and petrologic analyses are generally sufficient. In later more detailed and specific studies by the consultant, chemical analyses will usually be desirable.

\section{PHYSICAL PROPERTIES}

The desirable physical properties of dimension stones differ somewhat with intended uses. In general, durability and strength are the principal considerations, but other properties are also important, depending on whether the stone is used for exterior construction or interior, for buildings or monumental structures, for decoration, or for paving, flagging and curbing, etc. Physical constants, such as crushing and transverse strengths, abrasive index, absorption, porosity, and others are of value in judging a stone for a particular use. Unless he is instructed to the contrary, however, the field geologist, who is concerned with the general mapping and appraisal of an area, may leave such quantitative measurements to the operator, consumer, or consulting geologist or engineer, as a followup of the general survey.

Certain lithologic features are definitely related to durability, strength, and other physical properties, and are of value to the industry as fundamental background data that determine the adaptibility of a stone to various uses. Texture, fabric, uniformity, directional planes of weakness as expressed by natural cleavages, and other natural lithologic features bear directly on the specific properties of stone and become part of the geologic examination.

\section{CRUSHING STRENGTH}

The crushing strength (compressive strength), the measure of a stone's ability to sustain a load, seems to have little significance in choosing a dimension stone, except as noted below. Rare indeed is the commercial stone that has a crushing strength of less than 3,000 psi (pounds per square inch). Tests made at the U.S. Bureau of Standards (Kessler and others, 1940) on specimens of granite from 115 sources, representing 80 quarries or districts of the United States, give a range from 13,000 to $47,400 \mathrm{psi}$. An additional specimen of pronounced gneissic structure gave a value of $7,700 \mathrm{psi}$; the specimen showed some sericitization of feldspar. The common range in values for granites by modern methods of testing might safely be considered 
from 17,000 to 37,000 psi. Kessler and others (1940) give ranges for other classes of stone and some artificial materials, such as cast stone ${ }^{1}$ and brick, as follows:

\begin{tabular}{|c|c|}
\hline \multirow{2}{*}{ Marble } & Range (psi) \\
\hline & $8,000-27,000$ \\
\hline Limestone & $2,600-28,000$ \\
\hline Sandstone & $5,000-20,000$ \\
\hline Quartzite - & $16,000-45,000$ \\
\hline Serpentine & $11,000-28,000$ \\
\hline Cast stone & $1,600-21,800$ \\
\hline$\therefore$ & $1,000-20,000$ \\
\hline
\end{tabular}

Clearly, the values for crystalline rocks (granites, marbles and quartzites) are in the main higher than those for stratified sedimentary rocks. However, all the quoted values are very much higher than the loads imposed upon stones used in the highest structures. An oft-quoted example is the Washington Monument, 555 feet high, with base courses composed of marble and having a base load of little more than 600 psi.

What practical significance lies, then, in the crushing strength of a dimension stone? For one thing, it gives the prospective buyer assurance that the stone of his choice lies within an average range of indicated strength - that the stone compares favorably in this respect with other successful commercial stones of the class. There may, however, be a greater research implication in finding a significant relationship between values of crushing strengths and other physical or chemical features. It may be found that a stone of uncommonly low crushing strength for its class may have other detrimental characteristics of composition, structure, etc., that will cause it to deteriorate more rapidly, even though its original strength be far in excess of loads to be imposed upon it. Research in this direction has not been carried on suffiicently to demonstrate such relationship, though one granite producer has reported informally that he finds a consistent relationship between crushing strength and observed durability of stones long in use. Such research might be fruitful of practical results. Mineralogic and petrographic analyses made by a trained geologist would be an important part of such studies. The field geologist may not be expected, however, to do more than provide routine observations in these fields, while bearing in mind that such petrologic features as mineral composition, texture, and incipient alteration are pertinent to the problem. To go beyond this, to collect adequate samples and have tests made, is impracticable and should be left to those who are engaged in prospecting or development of the stone deposit. The obtaining of samples for testing is

1 Cast stone is a molded product made of fragmented natural rocks combined with a blnding material, chiefly cement, for uses similar to those of natural stone; it is generally designed to similate natural stone in texture, composition, and color. 
itself not only a time-consuming but also a highly involved process; it is a highly selective and quarrying type of operation. A prospective deposit will, however, be sampled and tested by the consultant.

\section{TRANSVERBE STRENGTH}

Tests for transverse strength have a more tangible value than do those for crushing strength because they measure the flexural strength of stones placed in positions of unequal pressure or bending, such as sills and caps for doors and windows. The standard test measures the modulus of rupture according to the established formula,

$$
R=\frac{3 W l}{2 b t^{2}},
$$

wherein $W$ is the imposed load at the middle of a span, $l$ is the length of the span, $b$ is the width of the specimen, and $t$ is the width. The ranges of values, in pounds per square inch, for the modulus of rupture for principal varieties of stone as tested and reported by the Bureau of Standards (Kessler and others, 1940) are:

\begin{tabular}{|c|c|}
\hline Material & Range (psi) \\
\hline Granite (29 specimens from 5 localiti & $1,380-5,55$ \\
\hline Marble & $600-4,000$ \\
\hline Limestone & $500-2,000$ \\
\hline Slate & $6,000-15,000$ \\
\hline Serpentine - & $1,300-11,000$ \\
\hline Sandstone & $700-2,300$ \\
\hline
\end{tabular}

That stones have often failed under transverse loads is apparent from observations. Unlike crushing strength under vertically distributed loads, the transverse strength is not uncommonly exceeded in actual use, because of differential loads and settling. There is no known relationship between crushing strength and transverse strength. Clearly, however, the textural characteristics of a stone will have a direct bearing on transverse strength. In particular the loosely aggregated stones may be expected to fail more readily under bending stresses than those of compact, interlocking texture. Here again, then, the examination of texture under the microscope can be related to practical appraisal of the stone.

Again, it is for the consultant rather than the field geologist to concern himself with actual determinations of transverse strength; but the field geologist may have opportunities to judge qualitatively by local observations a stone already in use.

\section{HARDNESS AND RELATED PROPERTIES}

The hardness of a stone is not to be confused with the hardness of the constituent minerals. It is, rather, a composite function of $527187-60-3$ 
these minerals. Moreover, it depends also upon the relative abundance of the different minerals, the mode of aggregation and texture of the grains, and even the porosity of the stone. Clearly, a stone of tight, interlocking texture will show greater resistance to penetration by pressure or impact than one of high porosity or one in which hard grains, such as quartz, are cemented by a relatively soft material, such as calcite. Also, for monomineralic rocks, such as quartzite or pure calcitic marble, the rock hardness may be considered practically synonymous with the mineral hardness.

There is no standard test for hardness of a stone, that is, to measure the composite hardness of components, though tests are available for measuring hardness, as resistance to penetration, at points of pressure. Simple pressure resistance is of little importance for construction stones, though it may be of importance for some types of test plates or for stone used under special conditions.

Closely related to hardness, but not synonymous with it, are toughness and abrasive hardness.

Toughness is the resistance to impact, a property that is important for stones that are in positions to spall readily under blows, such as corners and edges of steps, curbings, and the like. Except for the softer stones used for such purposes, or any stone subjected to exceptional impact, a test for toughness (or tenacity) is rarely needed for dimension stones.

Abrasive hardness is a very important property for dimension stones used for floor slabs, pavements, steps, stair treads, and the like. Impact and dragging will loosen and pluck mineral grains or parts of grains, especially those that possess good cleavage planes, even though such grains may be of superior hardness. Tightly knit, finetextured, smooth surfaces of stones composed of relatively soft minerals may prove to be somewhat more resistant to abrasion than loosetextured, porous stones of similar composition, for the wear is distributed more uniformly over areas.

Polymineralic rocks undergo differential wear, the softer or the more cleavable minerals being worn down or plucked more rapidly than others, leaving the harder or weakly cleavable minerals in relief. Large mica grains-especially those in "book" form, calcareous or argillaceous cements in sandstones, or carbonate veinlets in certain serpentines, for example, promote differential wear. In general, stones composed of the softer minerals are not recommended for usese where high abrasive resistance is required.

The mineral compositions and textures of rocks are, then, the principal lithologic features related to abrasive resistance and are, of course, normally recorded in routine geologic field mapping.

Several tests have been devised for determining the abrasive hardness of natural stones. One devised and used at the National 
Bureau of Standards (Kessler and others, 1940) gave the following results, which serve to compare in a general way the abrasive resistance of the principal classes of stone. The formula used for calculating the index of abrasive hardness $(H a)$ involves the original weight of the specimen, its bulk density, and the loss in weight caused by the test. The ranges in $H a$ values for various stones are given as follows:

\begin{tabular}{|c|c|c|}
\hline \multirow{2}{*}{\multicolumn{2}{|c|}{ Granite }} & \\
\hline & & \\
\hline Limestone & & $1-24$ \\
\hline Sandstone & & $2-26$. \\
\hline Slate -... & & 6-12 \\
\hline $\begin{array}{l}\text { Serpentine } \\
\text { Travertine }\end{array}$ & 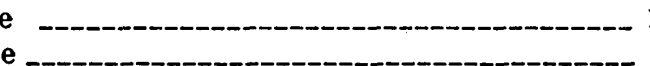 & $\begin{array}{l}13-110 \\
1-16\end{array}$ \\
\hline
\end{tabular}

The American Society for Testing Materials has established a standard test for measuring resistance to abrasion (see "List of standard methods of test and specification," p. 74).

The figures quoted above serve to indicate the variability in hardness for stones of all classes. The higher values for standstones were doubtless obtained from quartzitic varieties, and those of limestones from very dense fine-grained varieties. The superior resistance of some serpentine rocks is particularly noteworthy.

As is true of tests of other physical properties, sampling and testing lie. within the field of the consultant.

\section{POROSITY AND ABBORPTION}

The properties of porosity and absorption have an important and direct influence on strength and weathering and, hence, on durability of a stone. Porosity refers to the volume of pore space, and absorption refers to the amount of liquid that a stone will absorb upon immersion. Clearly, absorption is related to the volume of pore space, but the two do not have a consistent and directly proportional relationship to each other. Where pore spaces are of subcapillary size, absorption is consequently very low and negligible; capillary and larger spaces promote absorption and, hence, increase susceptibility to frost action and chemical weathering. Very large pores seem to favor easy drainage, which tends to minimize the effect of frost action. No simple rule for judgment in the field can be formulated, as the effect of porosity on absorption and weathering is conditioned by several factors, both internal and external.'

The shapes as well as the sizes of pores influence the absorption. If pores are connected, they naturally permit ingress of moisture throughout the stone. If the pores are more or less separate and of subcapillary size, water may penetrate but slightly; by the same token primary pore water (sap) will be retained. Stones of rela- 
tively high porosity may not necessarily show correspondingly high absorption, though high absorption will indicate high porosity. The determination of absorption is, therefore, of far more importance than the determination of absolute porosity. Of course, other things being equal, high porosity - especially if the pores are supercapillary -will directly influence the strength of the stone, but this effect is better determined by strength tests rather than by microscopic or other measurements of porosity.

The ranges in porosity for various stones, as tested by the Bureau of Standards (Kessler and others, 1940), are given as follows:

\begin{tabular}{|c|c|c|}
\hline Granite & Material & olume (percent) \\
\hline Marble & & $-.4-2.1$ \\
\hline Slate -.. & & $.1-1.7$ \\
\hline Quartzite & -2 & $1.5-2.9$ \\
\hline Sandston & ne _-_- & $1.9-27.3$ \\
\hline Limeston & ne ----- & $-_{2}^{2} 1.1-31.0$ \\
\hline Cast ston & one - & $-6.7-32.7$ \\
\hline
\end{tabular}

1 Rarely more than 0.6 percent.

2 The high value probably obtalned on coquina.

As the shape and size of pores are determined by the mode of aggregation of the rock, porosity is closely allied to structure as well as texture. Field observations may provide some degree of judgment of the porosity. Routine petrographic studies with the microscope will provide valuable textural data related to the porosity; such studies normally accompany the preparation of the field geologist's report, but he can well give additional attention to those formations that appear to be potential sources of dimension stones.

Absorption of water appreciably affects the strength of stone, quite apart from its promotion of frost action. For the most part the crushing strength is higher for dry than for wet stone. This is true even for granites whose texture is probably the most compact of all rocks, except perhaps some quartzites and marbles, owing to the closely interlocking texture. Differences in crushing strength of as much as 15,000 psi were reported for a few tests (Kessler and others, 1940). Exceptionally, a wet sample gave a higher value than the dry sample. By far, most of the tests showed differences. of the order of only 1,000-6,000 psi (round numbers). The tests showing the extremely high difference noted above were made in 1880 , long before improved and more exact methods of testing were established. However, the effect of absorption upon strength is adequately demonstrated. For granites the weakening is still far from affecting the strength of the stone with respect to any loads likely to be imposed upon it. For some other stones the effect may be serious. 
In general, it can be stated that rocks of compact textures-interlocking or mosaic-possess low porosities; such include commercial granites, marbles, and some slates and quartzites. Sandstones range from loosely compacted rocks of clastic texture, with various degrees of grain packing, to essentially interlocking crystalline or mosaic quartzites. Limestones also range from highly porous textures to dense fine-grained rocks or to tightly crystalline rocks that approach marble in lithologic type.

Specific tests for absorption are indicated for the quality appraisal of a. stone; this procedure lies outside the province of the field geologist, unless he is acting also in the capacity of technical consultant, in which case judicious sampling of a deposit becomes part of the field study. As stated before, routine mapping of an area does not ordinarily involve sampling and testing, unless specific search for stone resources is indicated as an essential part of the project. In any event, the geologist's function is to obtain preliminary, basic data as a background for more detailed technical studies. Usual lithologic descriptions will include qualitative statements on obvious aspects of porosity.

The. subjects of porosity and absorption have been considered here in some detail because of their importance with respect to the quality and durability of natural stones, and their dependence upon texture, a teature that merits the careful attention of the field geologist as well as of the consulting engineer and stone producer. The details are deemed to lend orientation with respect to this importance and, except as otherwise suggested, are not intended to indicate paths of research to be followed in routine geologic mapping.

\section{COLOR}

Color is an important property of stones used for building, monumental, and ornamental purposes. It does not affect the adaptability of a stone to structural use, except insofar as it may indicate the presence of deleterious minerals that influence the textural integrity, durability, or strength of the stone. For decorative purposes a stone is often selected for its color, which thus has commercial significance.

The architectural color of a stone-that is, its color as seen at a distance and in finished form as part of a structure-is, of course, due mostly to the color of the predominant mineral, though this is modified by the blending of all constituent minerals. The finer the texture, the more the colors are blended to give a general, uniform effect.

For many of the coarser textured polymineralic rocks (such as granites) the architectural colors cannot be adequately described from hand specimens, except in most general terms. A notable 
example is the Dedham grandiorite of Massachusetts, which contains pink and white feldspars, colorless glassy quartz, green epidote and chlorite, and a few remnants of black hornblende and biotite. In hand specimen, this rock appears mottled and variegated, but at a short distance it presents a uniform brownish-pink color. On the other hand, the granite at Bethel, Vt., which is composed primarily of white feldspar, colorless quartz, and muscovite, and with very little biotite, is notably white or very light gray in hand specimen as well as in finished form.

A color classification of stones is important to producers in two ways. First, an architect or designer may specify a stone of certain shade instead of stone from a particular quarry or district; this may be more restrictive, for in some districts, and even within individual quarries, the shade of color may vary appreciably. Second, for additions to existing structures it may be necessary to seek a closely matching stone if the original quarries have become inactive. For many eastern granites a standard color classification table has been devised, with the idea that granites of a given group will harmonize in actual use.

The architectural color of a stone varies also according to the type of surface finish, that is, whether rock faced, sawed, honed, hammered, or polished. For many crystalline stones polished surfaces show darker shades, and tooled (hammered, sawed, or honed) surfaces show lighter shades than do the natural broken (rock-faced) surfaces. If surfaces are to be inscribed, strong contrast between polished and tooled surfaces is generally desired. Thus a color classification must be based, in part, on the type of surface as well as use.

In the laboratory, the architectural color might well be determined by spinning a small plate of the stone sufficiently to blend the colors of the constituent minerals, and comparing the blended color with a standard color chart, such as that prepared in 1948 by a rock color chart committee and distributed by the National Research Council (Goddard, chm., and others, 1948).

Color differences may be noted along joints and slip planes. However, not all such discoloration indicates a detrimental degree of alteration. Iron-staining may penetrate the stone for an inch or even more without materially weakening the stone for some structural uses, such as ashlar blocks for small buildings, bridges, and decorative walls. Indeed, such stone is commonly selected for its architectural value, being known as seam-face stone. The seam-face stone, however, should not show signs of flaking or spalling but should present a firmly integrated surface. The coloration is probably due in large measure to iron solutions that have penetrated the stone from the joint or fault fissures rather than to alteration of the 
stone itself, though some alteration of the iron-bearing minerals of the stone is inevitable under such conditions. The geologist should be able to judge whether or not the stone has been materially affected by weathering. For large buildings in which the stone is to be used as veneer slabs, such seam-face material should be avoided and only completely sound and unaltered stone used.

Also, along some slip joints and faults, shearing produces slickensides that present smooth, tight surfaces. Green minerals commonly develop along such seams, giving a highly prized greenish seam-face stone. The alteration, unlike oxidation, may not extend appreciably into the stone; on the other hand, some slickensided surfaces chip easily because the minerals constitute a thin layer of gouge. The nature of the seam-face stone may easily be determined and appraised by the field geologist.

Seam-face stone is most common along the granitic rocks. A notable exception is the Roxbury conglomerate of the Boston Basin area, which was once used extensively for decorative buildings, especially churches. This conglomerate was derived largely from granitic rocks and has a very siliceous or arkosic groundmass; the rock is well indurated, almost quartzitic, and the abundant joints sharply transect both pebbles and matrix, apparently with equal ease.

The so-called black granites (p. 71) include the basic igneous rocks of very dark gray to black color, principally diorite, gabbro, and diabase. Because of their color and ability to take a good polish, these stones are used chiefly for decorative purposes. Furthermore, they are used mostly for interior paneling and wainscotting but to some extent also for exterior decorative paneling and monuments. The majority of black-granite deposits, particularly the finer grained diabasic types, are comparatively small and more closely jointed than are the lighter colored granites, so that many of them are not favorable for large blocks or quantity production. They commonly command relatively high prices as ornamental stones.

Some dense-textured basaltic rocks have also been marketed as black granites, but this is a misnomer in terms of the standard definitions for commercial granite and black granite. These rocks should be designated as basalt or trap rock. Because of their mode of origin-as sills, dikes, and flows-and their tendency to more closely spaced jointing, commonly columnar, relatively few of them yield large structural blocks. Locally, they are used for small foundation or wall blocks of rubble and ashlar types.

Some building stones change color shortly after exposure of a fresh surface. This color change is due most commonly to oxidation of ferrous iron in susceptible minerals, such as finely divided pyrite, epidote, and ankerite. For some limestones a similar color change has been attributed, in part at least, to oxidation of organic matter, 
as, for example, the Indiana limestone of trade, known also as Bedford oolitic limestone (Loughlin, 1929, p. 142). Again, the Niagaran dolomitic limestone quarried in the Chicago-Joliet area, though gray on fresh surfaces,' assumes a buff tint upon exposure; this may be due to oxidation of isomorphous ferrous carbonate, probably a common constituent of dolomitic rocks. Again, the normally blue-gray Berea sandstone, quarried extensively in Cuyahoga, Lorain, and Erie Counties, Ohio, changes to buff color, owing to oxidation of $\mathrm{FeCO}_{3}$ (Bowles, 1917; Weidman, 1942). It is said that this change is caused by an acidic industrial atmosphere, for in areas where the atmosphere contains no acid constituents, the original gray color is unchanged after many years of exposure. Such changes of color do not necessarily indicate that detrimental minerals are present in objectional quantities. (See further discussions under "Chemical weathering," p. 61.) Indeed, a uniform color change to a delicate buff tint is considered by some to be an architectural asset, provided, of course, that it is not accompanied by appreciable textural or structural changes in the stone.

In the detailed study of a stone for commercial use, it is clear that color is an important consideration because on the one hand it determines the use of the stone for certain decorative purposes, and on the other hand it may give a clue to deleterious mineral components or to weak textures. In such a case then, a microscopic examination is indicated. A more detailed study, however, is within the province of the consultant or of the geologist instructed to make a detailed lithologic study, rather than of the geologist engaged in general mapping; it is sufficient for the latter to be aware of the significance of color as a clue to structural, textural, and mineralogical features, and for him to report on the general color of the natural rock surface.

\section{DURABILITY}

Both producers and consumers of dimension stone desire a satisfactory method by which the durability, or life, of a stone may be determined in terms of physical constants. This has not yet been achieved for various reasons. Natural weathering processes are so slow that artificial tests must be devised to compensate for the time element. The principal difficulty lies in translating laboratory measurements into terms of natural environment, including the time factor. For example, induced crystallization of a salt in the pores of a stone by cycles of soaking, drying, and heating in a solution is presumed to duplicate the destructive action of frost and temperature changes in natural weatherings.

The artificial test cycle reduces the time span to practical limits, but the severity of such tests raises a question as to their validity in relation to natural frost action, which such tests are presumed to 
simulate. The method does, indeed, have merit and appears to have been quite successful in judging crushed stone for aggregate. Nevertheless, for dimension stones results have not been entirely consistent with observations on a stone either in natural occurrences or in constructional use. There is always a danger that satisfactory stones may be rejected on the basis of such a test, even though actual use through a span of years has demonstrated fitness of the stone for the particular use. A test of this sort is not geared to various natural environments, to composition of the stone, or to textural characteristics, for any or all of which a test that is rigorous beyond natural conditions does not bear a demonstrated simple and proportional relationship to the actual durability in time as affected by structure or composition of the stone. Moreover, a test specimen of stone selected, even carefully, from a large mass cannot truly represent the mass to the same degree of certainty that, for example, a dip of molten steel may represent the batch. The specimen possesses a relative lack of uniformity that is directly the result of the origin and mode of occurrence of the rock body from which it came. This is at least theoretically true even of rocks of magmatic origin; although for many of these, selection of an adequate sample for testing is commonly possible. Other lithologic classes of stone may depart widely from uniformity in this respect, reflecting even slight but influential lithologic variations within a block or mass. A test specimen actually represents only itself. In the examination of a quarry or outcrop, it is thus important for the geologist to note obvious natural textural, structural, and compositional variations in the stone in a qualitative way.

Regardless of the results and interpretations of specific laboratory tests, actual behavior of a stone in longtime use is important; so that, in the geologist's study of a stone district or quarry, observations on the behavior of the stone in local structures, monuments, and outcrops are pertinent to judgment of durability under the environmental conditions of the area.

The Committee on Natural Building Stones of the American Society for Testing Materials is currently engaged in considering the problem of durability with respect to tests suitable for specifications. Standard test procedures have been devised for determining various physical properties. (See p. 74.) Tests for transverse strength and absorption properties of building slate, and a test for resistance to abrasion for stones subjected to foot traffic have been established for specification purposes. For other stones, the applicability of the several standard tests to specifications have not yet been completely demonstrated. However, studies to date have suggested that a test for crushing strength may appropriately be indicated; the possible 
relationship between crushing strength and durability has been discussed on page 28 .

Durability is not definable, then, in general and simple terms, for it may signify somewhat different qualities according to mode and place of use. A stone that is highly durable for interior use may not withstand exposure to exterior conditions satisfactorily. Another stone may be highly durable for most exterior uses but prove unsatisfactory when exposed to abnormal environments. Still another may withstand weathering, but wear badly under abrasive conditions, as steps, pavements, and some curbings. Some foliated stones are adequately resistant to weathering when set "on bed" but disintegrate easily when set "on edge"; a notable example is the famous Triassic sandstone of the Connecticut Valley that in places showed spalling within less than a decade. Ries (1912, p. 198) cited an instance of the use of columns made of cipolino marble, in New York City, that showed pitting and loss of polish within 3 years; apparently the stone was not adapted for exterior use in that environment. On the other hand, such examples as the cipolino marble have no practical bearing on the general suitability of marble as a class for exterior use. Many buildings and monuments testify to the satisfactory use of marble throughout the world. Degrees of durability in practical time terms are not circumscribed quantitatively by lithologic types.

Various tables of data have been compiled to show the life span, in years, of stones. Such data are, of course, based on observations of stones in use, that is, in particular structures and at particular places. A well-known table of this sort was compiled some years ago for building stones in use in New York City (Julian, 1884, p. 364-393). This table, referring to the number of years before repairs were required due to discoloration or disintegration, gives, as examples, the life of fine-textured marble as 50 to 100 years; granite, 75 to 200 years; gneiss, 50 years to many centuries. The inapplicability of such data to general estimates of the life of building stones seems obvious. The table is quoted commonly and doubtless represents reasonably good estimates for the various stones in the particular structures and local environments as observed, but it cannot be translated into general terms of durability. Clearly, such tables, though they may be useful in a very general way for stones used in a given area, have little value for judging the general relative durabilities of stones, either of the same or of different classes. Pertinent data for a reasonably satisfactory estimation of durability would include specific details as to sources of the stone, mode of use, and environmental conditions.

How, then, may one define durability? Obviously it must relate to the length of time that a stone will retain its integrity and useful- 
ness as a construction material. To an architect, durability of a building or monumental stone is measured by the length of time it takes before pitting, scaling, spalling, or loss of polish make it unsightly. To a construction engineer it might mean the endurance of a stone in maintaining a required structural strength and form. These would not become identical measures, for a stone may show some signs of superficial weathering without its strength-its ability to resist stresses-becoming materially impaired. It may retain its structural integrity long after it has lost its finish. Of course, long continued weathering would ultimately have a telling effect on strength, but there is no consistent or proportionate relationship between these two features, and the time span involved may be far beyond practical consideration.

It is quite desirable to have the durability defined in scientific terms and to seek some measure of it through laboratory procedures. Physical constants, such as crushing strength, tensile strength, absorption and porosity, and loss of weight by spalling under accelerated weathering tests are not, in themselves, definitive-either individually or together - of the lasting qualities of a stone, unless such tests are closely keyed to sources of the samples and to modes and conditions of use. Moreover, tests devised for one kind of stone, as for example, marble, will not necessarily be suitable for another, for example, granite.

Much may be learned, however, of the durability of a stone by observing its behavior in nature and in local manmade structures. The geologist is competent to make such observations, relating them so far as possible to composition, texture, and structural features. He can hardly expect to go beyond this in a general survey, but these observations may have definite value. His statements should, however, be specific as to use, position, and environment, related clearly to lithologic properties.

\section{PRospecting}

In earlier days of community settlement and development, deposits of stone suitable for local construction were sought in much the same manner that other types of mineral deposits were prospected. In some respects, of course, the task was much simpler, for rock outcroppings were generally more or less common knowledge and assays or analyses were not involved. If a rock formation appeared hard, massive, and blocky it satisfied preliminary requirements.

The necessity for finding natural-stone construction materials probably faced a growing colony as soon as the log cabins and blockhouses were outgrown, and larger buildings with sound foundations and basements or dwellings with cellars were conceived. Bricks were favored as a major construction material where local clay deposits 
were available or importation as shipping ballast was economically possible. But with this came the need for more massive blocks of stone to be used as foundation and basement walls, retaining walls, dams for mill ponds, and the like.

Surface slabs of stone, "field stones," and boulders, where available, were shaped to these uses. Stone buildings appeared where favorable rock materials were plentiful. For instance, the famous Kings Chapel in Boston, Mass., was constructed of blocks fashioned from large glacial boulders of granite that were particularly abundant in the nearby Quincy area. Elsewhere in the country slabs and blocks of sandstone, limestone, and the uppermost thin sheets of granite masses in areas of crystalline rocks were removed from outcroppings and to easily accessible depths. As the walls of large stone buildings were thick and required thicker, sounder, and more massive blocks of stone, the need for favorable sources of larger and sounder blocks grew, and possible sites for deeper quarries were sought and exploited.

Except for large and remote areas of new development and rapid growth, as noted below, prospecting for dimension stone now consists in large measure of reexamination of outcrop areas and old quarries in established districts, and areas for expansion of operating quarries. It is incumbent upon the field geologist to map the distribution of formations or parts of formations that are of demonstrable value as dimension stones, so far as indicated by active or abandoned workings. The purpose of this paper is primarily to make him aware of the geologic and lithologic properties of a stone that are pertinent to prospecting as well as exploitation. His observations are of value to operators who seek reserves for expansion of their present workings, or who wish to meet diversified demands by. developing new quarries or by acquiring and reopening abandoned quarries in other districts. Large structures demand large quantities of uniform stone to be delivered within a relatively short period. Not only does the quarrying of dimension stone thus become more concentrated than formerly in fewer and larger scale operations, but the need to block out reserves for future expansion of the existing quarries is always a current problem.

Prospecting is not confined, however, to expansion or redevelopment in established districts. Civil engineers, planning large construction projects in sparsely settled or remote areas and in other areas where a quarrying industry has not been established, often must seek sources of stone suitable for foundations, buildings, dams, or retaining walls. The availability, suitability, durability, and cost of local stone are weighed against cost of imported materials, whether stone or cement. Even where cement is to be used for large dams, dimension stone, if available, may be needed for other related 
structures, advantages in cost and durability being demonstrated. When large engineering projects are planned-as for water control and hydroelectric power-a basic geologic study of the area should always be made, and this study should include an appraisal of possible stone resources within a practicable distance. But in any area of general mapping, the field geologist should become cognizant of any stone deposits that may have potential as construction material.

Efficient quarrying methods are based fundamentally on the operator's ability to evaluate and use lithologic, textural, and structural features as a guide in development as well as prospecting. Such features as bedding planes, fracture systems (joints and faults), natural cleavage directions, veins, textural and compositional variations, depth and nature of weathering, thickness and nature of overburden, and topography of the terrain are all related to his development operations. The geologist's task, therefore, is not only to map surface distribution, but also to map or otherwise record the geologic data relating to these features insofar as they are determinable. Thus, the geologist's work is conditioned in part by ordinary field methods, in part by industrial factors. For an area in which quarries, active or abandoned, already exist the task is relatively simple. For virgin areas where he is dependent entirely upon study of outcrops, he will be able only to generalize and to record but few specific data. Interpretative projection of surface data into the third dimension, with appropriate qualification, is corollary to his study of potential stone deposits.

The larger companies commonly explore by core drilling. The geologic map, structural data, and cross sections resulting from a careful geologic study can serve as a very helpful guide in the placing of drill-holes and the interpretation of subsurface conditions pertinent to successful quarry development.

\section{EXAMINATION OF DEPOSITS}

Geologic mapping of an area should provide the basic data related to the modes of occurrence, stratigraphic positions, distributions, and - so far as revealed by surface exposures-the structural relations of known mineral deposits. These data serve as a general guide to prospecting or further development.

The apparent simplicity of commercial stone deposits as compared with deposits of ores and most nonmetallic industrial minerals may easily lead a field geologist to think that a general map of bedrock formations and a cursory statement regarding their lithologic character and general thickness or size are sufficient for purposes of potential resource appraisal. Such data are, of course, the first requirements for reporting a potential deposit. Nevertheless, a more specific appraisal is needed for areas where constructional or indus- 
trial developments or expansion are probable, or are reasonably probable, in the not too distant future. Whether or not a given area is considered to possess such likelihood may be a matter of the geologist's opinion or of his instructions regarding the purpose of the project. Indeed, the selection of an area for general mapping is based commonly on industrial or engineering needs, so that mineral deposits of all kinds then acquire more than superficial interest, and in some instances indicate a detailed treatment within the bounds of routine field study.

The nature of stone deposits and of methods of their exploration and exploitation require rather distinctive procedures of study, for unlike most mineral deposits the rock masses are large and yield bulk products. Physical properties, textures, minor structures, and even geographic situation determine the suitability of a rock formation to exploitation, whereas deposits of ores and of most industrial minerals depend primarily on chemical nature, and on localization and concentration of specific minerals.

The following schedule is applicable to dimension stones of all lithologic classes. It is for the guidance of the field geologist in examining either undeveloped deposits or quarries of dimension stones. Obviously not all items are applicable to each class of stone, nor is it always possible to report on all items that are pertinent. Old quarries will, of course, yield more comprehensive data than will outcrops of undeveloped deposits, so that where geologic mapping is performed in established districts careful examination of existing quarries is desirable.

Because much of a field geologist's study of a potential or developed commercial deposit consists necessarily of the recording of many kinds of physical data, it is advantageous to follow such a schedule so that unconscious omission of important data may be avoided. However, a scientific study should not be circumscribed intellectually by such a conventional and limited approach as strict adherence to an outline. It is urged that this principle be kept in mind, to the end that scientific as well as technical interests may be followed. An active, though well-controlled, scientific imagination contributes to both the theoretical and practical facets of geologic science. Use of an organized outline for field study should in no way displace extralateral observations and the customary taking of comprehensive field notes.

When study of potential stone resources of an area is made in connection with regular geologic mapping, it may not be feasible or practicable to include all the pertinent technical data within the brief text of the quadrangle geologic map. The results may be appropriately summarized and epitomized under a section on economic geology to serve as a general guide and appraisal of the stone re- 
sources. However, the detailed record might well be appropriately filed for public reference, and its accessibility so indicated in the text. Such data are, of course, not available to the public except under some form of publication, either during the progress of field studies or at a subsequent time.

For a more complete industrial appraisal, the consultant will wish to pursue the more technical aspects of tests for various properties, analyses, and quantitative mapping of variations within the rock mass.

\section{SCHEDULE FOR EXAMINATION OF DEPOSITS AND QUARRIES}

General features:

Location of deposit or quarry, name of district (if developed), ownership (quarry)

Size of quarry (approximate)

Formation and trade name

History of operation

Geologic features:

Distribution of formation

Stratigraphic position

Thickness of formation and of workable part

Lithologic classification and description, notable variations

Petrographic description and classification

Mode of origin and occurrence, form

Major structural elements: attitude, folds, etc:

Contact relations to other formations

Texture and fabric: variation, relation to other features

Fractures and fracture systems

Joints: attitude, distribution, spacing

Faults : attitude, displacement, width of shattered or gougy zones

Rock cleavage: natural planes of parting, relation to other features

Veins and dikes: nature, distribution, attitude, relation to other features

Inclusions and segregations: distribution, nature

Overburden : nature, thickness

Weathering: depth, nature, relation to other features

Industrial features:

Classification, similarities with other commercial stones of class

Use of the stone, specific structures as examples

Topography

Accessibility

Working facility, structural elements

Workability of the stone, production and milling of finished blocks into architectural or monumental units

Color

Reserves, development reserve areas

\section{LOCATION OF DEPOSIT OR QUARRY}

The geologic map serves to locate the geologic formations, but: both active and inactive quarries should be specifically symbolized. For an established district, confusion often arises from duplication 
of quarry names where a single company operates more than one quarry. When possible quarry locations should be indicated with reference to readily identifiable and permanent towns and villages or other cultural features, as "one-third mile N. $35^{\circ} \mathrm{W}$. of Brentwood," the point of reference being the usually recognized central landmark of the settlement. Such reference points as schoolsespecially rural schools-churches, town halls, and the like are of temporary nature, and points such as "bench mark 205," "crest of hill 469" may disappear from subsequently revised editions of base maps, besides sometimes requiring further identification themselves. Locations by established coordinate systems, by latitude and longitude, or by townships, ranges, and sections (where established) are always exact but not always easily identified by the layman. Most districts and many quarries are named after nearby settlements or well-known topographic features, as "the Salisbury granite district," "the Jonesboro quarry," and the "Mount Waldo quarry."

Company designations of quarries should be given, as "The upper quarry," "west quarry," etc., but these should be further specifically identified with reference to other quarries of the area.

Sometimes confusion results from the use of a locality name for both an operating company and a quarry operated by another company, as, "the Greystone area," "The Greystone Granite Co. quarry," "the Old Greystone quarry," and "The New Greystone quarry," all operated in the vicinity of Greystone, N.C.

\section{SIZE OF QUARRY}

Dimensions of quarries, including depths, are ephemeral and may be given in approximate form by pacing a reasonably close estimation without resorting to surveying techniques. Dale (1923) found it adequate to give dimensions in such round numbers as "about 1000 by 500 feet $* * *$ and ranges in depth from 20 to 75 feet, averaging about 40 feet" or " 150 by 50 feet, and 10 to 25 feet in depth." A simple oriented sketch plot may well be added. More exact measuring and plotting will be indulged in by operators, for purposes of purchase or exploration, but are not ordinarily needed for a basic areal geologic survey. It is probably more important, however, for the geologist to estimate vertical dimensions of pit quarries more closely than horizontal dimensions, for depth operations may be more significant with respect to workable horizons. Hillside, "shelf," quarries present a different aspect in that the approximate height of the backface should be given.

\section{FORMATION NAMES}

Both U.S. Geological Survey nomenclature and other nomenclature in literature should be given, or their identity indicated. 
The formation name as it appears in literature is not always suffcient to identify the commercial deposit. Trade names have occasionally been used by geologists to establish a formation name; but this is rarely satisfactory, because quite commonly the same widespread formation has provided more than one quarry district whose products appear under different trade names. Moreover, formations are of comparatively wide distribution, and identification of the local quarry product with the technical formation name may imply a possible broad distribution of similar stone for prospecting purposes.

\section{HISTORY OF OPERATIONS}

This subject may be treated very briefly. A few salient points on past operations has some value to operators in regard to successful marketing of the stone and hence its adaptability to dimension stone uses.

\section{GEOLOGIC FEATURES}

\section{DISTRIBUTION OF FORMATION}

The geologic map will, of course, indicate distribution in a general way; but because of map scale or paucity of exposures, it may not be practicable to indicate on the map also the distribution of workable portions or horizons. A brief guiding statement is of value, particularly as to horizon markers or key beds that would aid in prospecting.

\section{STRATIGRAPHIC POSITION}

Relationship to other formations of the local stratigraphic column and correlation with recognized units are, of course, standard procedures in geologic studies. Commonly only certain horizons of a geologic formation have been exploited. On the other hand, in some districts quarries have been developed in different stratigraphic positions of the same formation, and correlation of them with each other has been assumed. The geologist should clarify this confusion.

\section{THICKNESS OF WORKABLE PART OF FORMATION}

This feature will be revealed in part by quarries. Any probable or apparent limits are important in future development. Not all parts of a geologic formation are necessarily of potential value; this is particularly true of bedded formations, of which but one horizon may have industrial importance. In this respect geologic nomenclature and industrial nomenclature may differ, so that the trade name is not synonymous with the geologic name, and confusion may be avoided by making. a clear distinction. 


\section{IITHOLOGIC CLASSIFICATION AND DESCRIPTION}

The lithologic classification is a regular megascopic field identification not requiring petrographic study. Compositional qualities may be indicated in the nomenclature, as granite gneiss, hornblende granite, schistose quartzite, micaceous sandstone, calcareous sandstone, siltstone, dolomitic marble, fossiliferous limestone, diorite, diabase, and similar terms. Hand-specimen descriptions will include other mineralogical and textural features, such as a field geologist will ordinarily record. This designation will key into the "commercial lithologic classification" (p. 7) that should be designated also under "Industrial features" (p.7).

\section{PETROGRAPHIC DESCRIPTION AND CLASSIFICATION}

Here should be summarized the results of any petrographic study. The petrographer's nomenclature belongs here, together with a more complete statement of mineralogic composition, indicating minor minerals, objectionable minerals, alterations, and textural characteristics. Quantitative composition may be estimated. Chemical analyses are required only when special purposes or needs of the project are indicated.

\section{MODE OF ORIGIN AND OCCURRENCE; FORM}

The geologic terms for mode of origin and form are applicable here, as sedimentary, bedded, tabular, lenticular, etc.; igneous, dike, sill, sheet, stock; volcanic; etc. A statement of the shape of the formation and of the commercial portion is of value to the operator.

\section{MAJOR STRUCTURAL ELEMENTS}

For a tabular deposit the attitude as well as the thickness are important in determining the mode of development of a quarry. So far as possible such deposits are quarried along the strike if the dip. is more than a very few degrees. Most sandstones and limestones are quarried in horizontal, or nearly so, beds to shallow depths (as compared with granite and marble), with removal of overburden. If the beds are markedly inclined quarry costs increase greatly owing to the necessity for developing underground rooms and pillars. Strongly folded sedimentary rocks are usually unfavorable for economical quarrying. Marbles and slates, on the other hand, occur commonly as strongly folded beds and the quarrying methods are conditioned by major as well as minor structural features. Marbles are, however, compact and texturally strong, permitting development of large rooms in thick beds by underground mining methods. In quarrying slates, on the other hand, advantage is taken of the rock cleavage, which is commonly steep to vertical and permits deep quarrying 
along the strike. Granitic rocks, being comparatively isotropic and massive, permit development along three directions so that wide, long, and deep quarrying is possible. Thus the forms and major structural features of stone deposits in part determine the quarrying method.

\section{CONTACT RELATIONS}

Sharp contacts, transitional zones, angular unconformities, fault boundaries, and the like have important relations to the quality and selective quarrying of stones and should be carefully described.

\section{TEXTURE AND FABRIC}

Texture relates to the size and shape of grains; fabric relates to the arrangement and orientation of grains, and involves a structural sense. However, various petrologists use the terms somewhat differently-some with complete synonymity, some with partial synonymity, and some use texture entirely. To paraphrase, "It is all very confusing," said Alice. "Not at all," replied the caterpillar, "a word means what you want it to mean." Obviously there is some interdependence of the terms, for it is generally difficult to describe the mode of aggregation of a rock without involving the presumed senses of both texture and fabric. Therefore, use of the term "texture" in a broad sense to include size, shape, arrangement, and mode of aggregation of grains will serve practical purposes in the descriptions of commercial stones.

As pointed out previously, the texture influences several of the important physical properties of stone-durability, strength, porosity, bulk specific gravity, cleavage, hardness, and workability. By the same token it affects directly the chemical as well as physical susceptibilities to weathering. It contributes also to the aesthetic choice of a monumental stone. Texture is, consequently, a very important characteristic of commercial stones. It merits careful description, including its variability within the deposit. It can be defined in the familiar geologic terms-fine, medium, or coarse, etc.; equigranular, inequigranular, crystalline, granitoid, mosaic, granulitic, rounded, clastic, etc.- and as to parallel orientations of minerals.

Porosity depends on texture in the broad sense used here, as it relates directly to absorption and hence to resistance to frost action, chemical alteration by penetrating solutions, etc. It relates also to bulk specific gravity of the stone. It is usually not necessary for the field geologist to determine the porosity quantitatively, but insofar as qualitative observations can be made such information through a petrographic study of texture is of value: The consultant, on the other hand, will need to make, or have made, tests on porosity and absorption. 
Commercial granites are described as fine, medium, or coarse grained, and commonly also as porphyritic, even granular, uneven granular, and the like. Ordinarily, the actual size of grain is not stipulated, but most of the industry apparently accepts a textural classification by Dale (1923, p. 9). He defines grain sizes of commercial granites according to size of feldspar grains in an "evengrained" granite as follows: coarse, over 0.4 inch $(1 \mathrm{~cm})$; medium, between 0.4 and 0.2 inch; fine, under 0.2 inch. Obviously such textural classification can be only approximate, for no granites are truly equigranular; indeed, the grain size may range widely. Moreover, the average diameter of grains cannot be closely determined without laborious petrographic measurements, which, for general purposes of field classification, would not be of value commensurate with the time and labor involved. A careful judgment of the texture in outcrops and hand specimens will ordinarily suffice.

Commercial sandstones include all clastic sedimentary rocks embraced by the geologists' terms "siltstone," "sandstone," "conglomerate," and "breccia." In general, the bluestones include siltstone and very fine grained sandstone. (See p. 73.) The industry has not established standard definitions for textures of sandstones, so that the terms "fine," "medium," and "coarse" are used inexactly and differently by various producers. A geologist can well be guided by the textural scale adopted by Pettijohn $(1929$, p. 13), in which the grain sizes for silt and siltsone range from $1 / 256$ to $1 / 16 \mathrm{~mm}$, for sand and sandstone from $1 / 16$ to $2 \mathrm{~mm}$, for granule sand from 2 to $4 \mathrm{~mm}$, for pebble conglomerate from 4 to $64 \mathrm{~mm}$, and for cobble conglomerate above $64 \mathrm{~mm}$. For commercial purposes, it would be practicable to consider fine-grained sandstone as less than $1 / 16 \mathrm{~mm}$, medium-grained from $1 / 16$ to $1 \mathrm{~mm}$, coarse-grained from 1 to $2 \mathrm{~mm}$, very coarse grained from 2 to $4 \mathrm{~mm}$, and conglomerate above $4 \mathrm{~mm}$. In the rare instances for which a petrographic textural classification is desired-ordinarily beyond the scope of the geologist's general survey-the Pettijohn classification could be followed more closely.

Commercial marbles are sometimes described texturally as fine, medium, or coarse. Again, the industry has not agreed on an exact classification. As a guide, however, Dale's textural classification of Vermont marbles (Dale, 1912) could be followed, that is, extra fine, $0.06 \mathrm{~mm}$; very fine, $0.10 \mathrm{~mm}$; fine, $0.12 \mathrm{~mm}$; medium $0.15 \mathrm{~mm}$; coarse, $0.24 \mathrm{~mm}$; extra coarse, $0.50 \mathrm{~mm}$. This classification is obviously approximate for the general average grain size. Like the granitic rocks, however, grain sizes in a specific marble may range rather broadly. Measurements are, again, of course, a matter of close petrographic measurements and, hence, not to be indulged in for the ordinary field examination, the above quoted figures being 
for general guidance of the field geologist. The so-called statuary marbles are fine grained, white, and usually with a translucent quality in thin plates.

\section{FRACTURES AND FRACTURE SYSTEMS}

The spacing and distribution of joints (open seams) have a direct bearing on the mode of development of a quarry, as well as on the value of the product. Besides limiting the sizes of blocks, major joint systems provide natural breaks ("headers") along which sections of the quarry are opened (pl. 2).

Veriical or steeply dipping, even, and widely spaced joints in rectangular systems are most favorable. Zones of closely spaced joints (sheet jointing) are unfavorable, not only because the material within them is worthless, but also because weathering and alteration by ground water are apt to be more pronounced in such zones and more penetrative into the adjacent blocks. Moreover, the forces that developed sheeted zones were commonly of torsional or shear nature and, consequently, may have deformed the mass in other ways. Diagonal joints of various attitudes and curved joints intersecting at oblique angles form angular blocks of shapes unfavorable for easy quarrying or shaping of blocks. Even some granite masses are so deformed in this fashion as to render an otherwise good stone worthless for dimension purposes. Commonly this condition reflects a geologic history involving more than one episode of major regional deformation.

In granites so-called bedding joints are usual, though not universal. These fractures separate the rock mass into sheets or beds, (pls. 2,3) and are believed to result from release of load by erosion, perhaps assisted slightly by insolation in the uppermost sheets. It seems improbable, however, that insolation will affect more than the upper few feet of the rock. The sheets ordinarily are increasingly thicker with depth (pl. $3 A$ ), and in some deep quarries sheeting is absent below a certain depth. The surface sheets may be very thin-in places only a few inches thick-but the thinness of sheets in an outcrop area is not to be construed as indicative of thin sheets at workable depths. In general, the sheeting planes or surfaces follow the contouring of the ground surface (pl. $3 B$ ), dipping with ground slopes (usually at somewhat lesser angles but in some places at slightly greater angles), being essentially horizontal beneath flat areas. At depth, however, all sheeting tends to become horizontal as well as thicker. Because of their variations in thickness, their general conformity in attitude with the ground surface at shallow depths, and their consistent horizontality (or nearly so) at depth, the upper thin sheets of a quarry are commonly lenticular or wedge shaped, and so overlap and toe-in or interlock (pl.4). 
In some granite quarries, for example Mount Airy, N.C., sheeting is absent and artificial freeing of sheets by special techniques must be resorted to in the quarrying operations.

Sheeting is, therefore, one of the most important structural features to be studied in a granite mass, but its characteristics must generally be observed in quarries, as outcrops reveal little, if any, data-even by inference- on sheeting at undisclosed depths in the deposit. Consequently, the study of either abandoned or active quarries in a district is of first order importance in the appraisal of a granite deposit. It is pertinent to remark, too, that ordinarily the conditions observed in a quarry will pertain to undeveloped resources of the same stone elsewhere in the district, where similar topographic features exist. Operators often explore the sheet characteristics of an undeveloped area by core drilling.

The stone may also have been deformed by apparently tight, minute, or even incipient fractures that are not discoverable until it has been milled, finished, or subjected to crushing or transverse strength tests. Some are of "hairline" nature recognizable only on polished surfaces. Some are minor fractures that have been. healed by introduced minerals, such as quartz, calcite, and-particularly in granitic rocks-by micaceous minerals, hornblende, epidote, and others. They are, of course, detrimental if they cause the stone to break under imposed loads, or if they become obvious on polished surfaces of monumental or ornamental stones. In some instances they become obvious on weathered surfaces. Rather commonly, too, they cross natural cleavage directions at various angles and so may lead to angular breaking of the blocks. Obscure incipient joints may be discovered usually by cobbing of small blocks by hand, or by wetting a fresh quarry face. Quarrymen apply special terms to minute veins and incipient joints-such as "hairlines," "shakes," "vents," "starts," and "blind seams."

Faults are sometimes detrimental features because of (a) development of gouge zones, (b) brecciation or shattering of adjacent parts of the rock, (c) trends and attitudes diagonal to principal joint systems, (d) strong and penetrative weathering along a wide zone, (e) discordance of their positions with respect to directions of quarry development, and (f) displacement of workable beds, especially in stratified formations. Normal faults are commonly less objectionable than reverse or thrust faults because they are generally steep, were formed under conditions of tension and so have caused less shattering and brecciation, and because their attitudes and distribution accord more closely with major joint systems.

The geological examination will, therefore, include careful study of joints and faults as to nature, distribution, attitudes, breccia- 
tion, and effects on natural weathering. (See also remarks under "Weathering," p. 59.)

\section{ROCK CLEAVAGE}

Natural planes of cleavage influence both quarrying and dressing methods of dimension stones. Commonly two, sometimes three, directions of cleavage characterize rock masses, though they are by no means of equal ease in breaking. Indeed, for many of the crystalline rocks the cleavages are not: readily induced in small blocks or specimens by hand cobbing. To the quarryman identification of the planes of breakage is essential to economic operations for they influence the techniques of opening and developing the quarry, freeing of blocks, and the fashioning of mill stock. Skilled quarry workmen control breaking along natural cleavage directions by wedging with plugs and "feathers." Examination of a quarry will readily disclose cleavage directions that may not be identified in natural exposures.

The direction of easiest cleavage is called the rift, the second easiest is called the grain. If present at all, the third and most difficult is called the: head grain. Quarry blocks are broken in three rectangular directions for easiest extraction from the ledge as well as for economical fashioning with minimum waste. If there is a distinct head grain to the stone, the quarrying and milling operations are facilitated; if there is no head grain, the third rectangular direction is commonly called the "hardway." The terminology of stone cleavages varies somewhat in different districts and with different stones, but the term "rift" is consistently used for the easiest cleavage. In some districts "run" has been used in place of "grain."

Where one or more of the cleavages is very weak, unskillful operation may ruin blocks by inducing irregular or curved breaks, promoting excessive quarry waste, and requiring otherwise unnecessary cobbing to produce usable blocks. In large quarry operations, however, modern methods of extraction by the use of channeling machines and wire saws, in place of drilling and use of explosives, are less dependent upon the attitudes and ease of secondary cleavages than was formerly the case. Large blocks freed along the rift direction are separated within the quarry. Nevertheless the quarryman makes judicious use of all natural directions of cleavage.

One of the two major cleavages of granites is almost always horizontal, and the other is generally vertical, on nearly so. In 101 New England quarries Dale (1923) recorded 49 as having horizontal rift, 46 as having vertical rift, and 6 as having inclined rift ranging up to $40^{\circ}$ to the horizontal. A good horizontal rift favors the economical development of benches in the quarry. For most districts the rift was found to be constant; most New Hampshire quarries and quarries in the Milford district, Massachusetts, showed consistently horizontal rift. Quarries of the Barre and Woodbury dis- 
tricts, Vermont, and Rockport and Quincy districts, Massachusetts, showed consistently vertical rift. Some districts in Maine showed vertical, others horizontal rift, but most quarries in a given district were consistent; an exception was found in the Jonesport district when one quarry showed horizontal, and another, nearby, showed vertical rift. In some districts where the rift is vertical the terms "lift," "rift," and "hardway" have been applied to the three rectangular directions of breaking. In a few places (example, Quincy, Mass.) both the rift and grain are reported to be approximately vertical and at right angles; here the sheets are lenticular and undulatory. It appears, therefore, that there is no consistent relationship between either rift or grain and sheets or bedding (as defined on page 49) in granites. Bedding tends to become horizontal at depth-if developed there at all-but is commonly inclined at or near the surface, so that the horizontal cleavage direction intersects the bedding at various angles. Moreover, in some quarries a split to free blocks horizontally may tend to rise or fall away from the horizontal cleavage-whether it be rift or grain-according to the direction from which the splitting is done. It appears, therefore, that the "run" of the split is influenced by several conditions; it may be a resultant between the natural bedding cleavage and release of stresses in directions unrelated to the cleavage direction. At any rate, it is clear that careful determination of the natural cleavage directions and the directions in which the stone will actually break with respect to the already developed sheets are of great importance to the operator and will affect the economy of the operation.

The principal cleavage of slates may not follow the bedding, which may be greatly obscured by the cleavage. Being due to the development of oriented microscopic platy mineral grains rather than to weak cohesion between sedimentary layers, it is a form of very thin foliation. Within a single bed it is quite uniformly developed but may change markedly in quality, and to some degree in orientation, in passing from one bed to another, so that quarry development follows the sedimentary beds rather than the cleavage. The photograph, plate 5, shows relations of bedding to cleavage in a closed syncline in a slate quarry where the cleavage is parallel to the limbs of the syncline and crosses the trough. In an earlier bulletin, Dale and others (1914, pls. 23, 24) show various relations between cleavage, bedding, and joints, as observed in numerous slate quarries in New York and Vermont. The quality of slate and, hence, the value of a slate deposit depends, among other things, upon the uniformity and smoothness of its cleavage planes. It is also conditioned by secondary shear effects, such as slip cleavages, minute folds, crinkles, and incipient fracture cleavages, whose planes and axes intersect the slaty cleavage at various angles. Many deposits of slate with ex- 


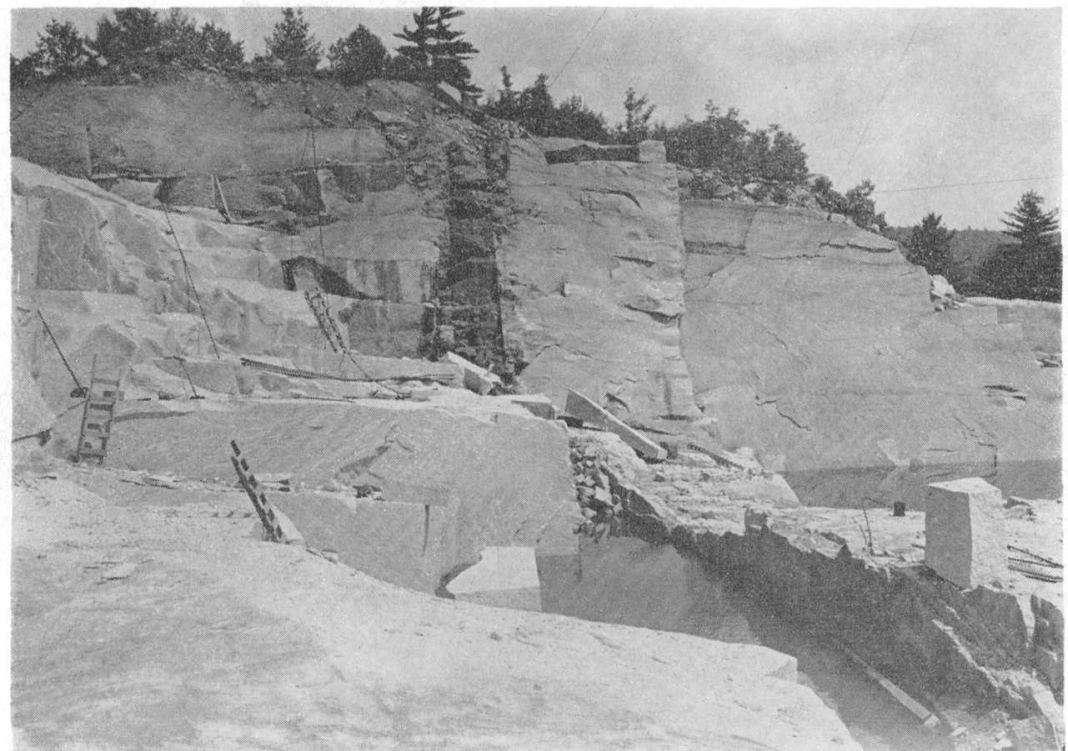

GRANITE QUARRY SHOWING "HEADERS," DIKE, AND SHEETING

Granite quarry (shelf type) in giaciated region (New Hampshire), showing irregular lenticular sheeting; major joints ("headers") in two directions at right angles; diabase dike 3 to 4 feet thick with contact zones 1 to 2 feet thick of shattered, discolored, and sheet-jointed granite (the dike follows one of the major joint systems); thin overburden of bouldery glacial drift in sharp and smooth contact with bedrock; spalling of corners and edges of sheets due to bursting of the stone owing to release of internal stresses during quarry operations. 


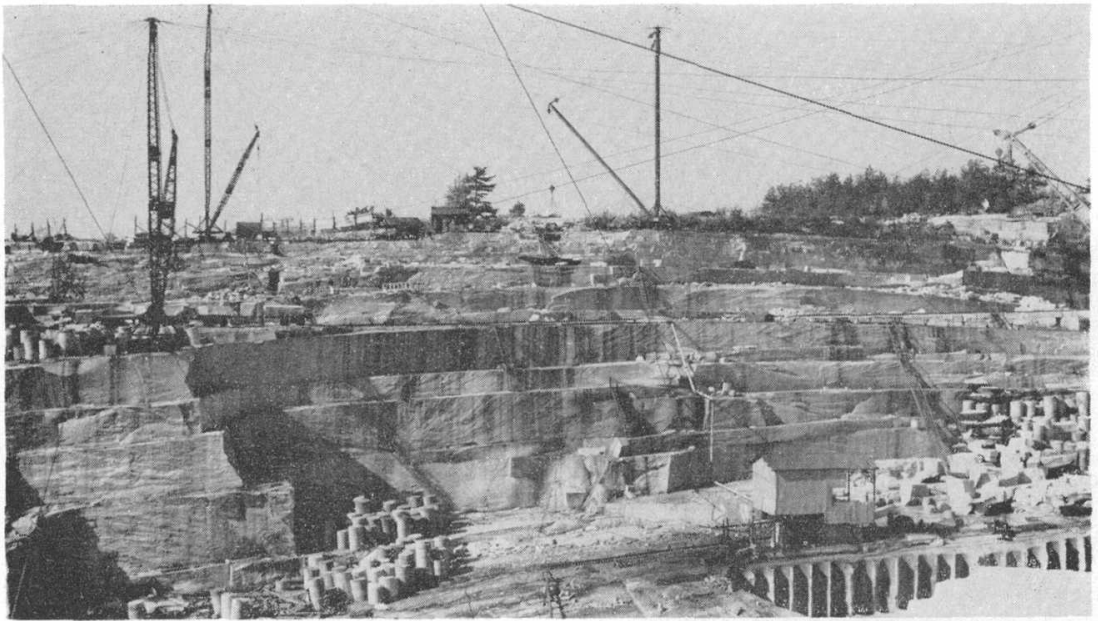

A. GRANITE QUARRY SHOWING HORIZONTAL SHEETS AND INCREASE IN THICKNESS WITH DEPTH Granite quarry (Massachusetts) showing essentially horizontal sheets that increase in thickness with depth. The lower sheet, at the left, is about 18 feet thick. The rift is horizontal; the faces have been split along the grain.

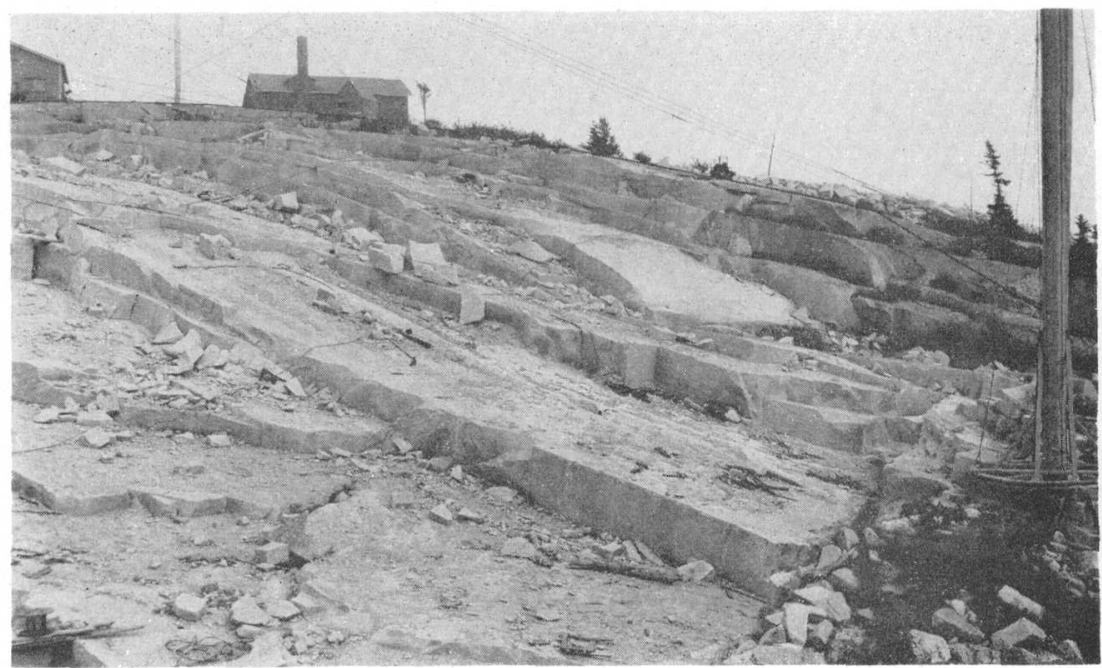

B. GRANITE QUARRY SHOWING RELATION OF THIN SHEETING TO TOPOGRAPHIC SURFACE

Granite quarry (shelf type), Maine, showing thin sheets of upper part of quarry, conforming in dip with the topographic surface. The sheets have been split along the rift (vertical). Elsewhere in this quarry the deeper sheets range up to 25 feet in thickness. 


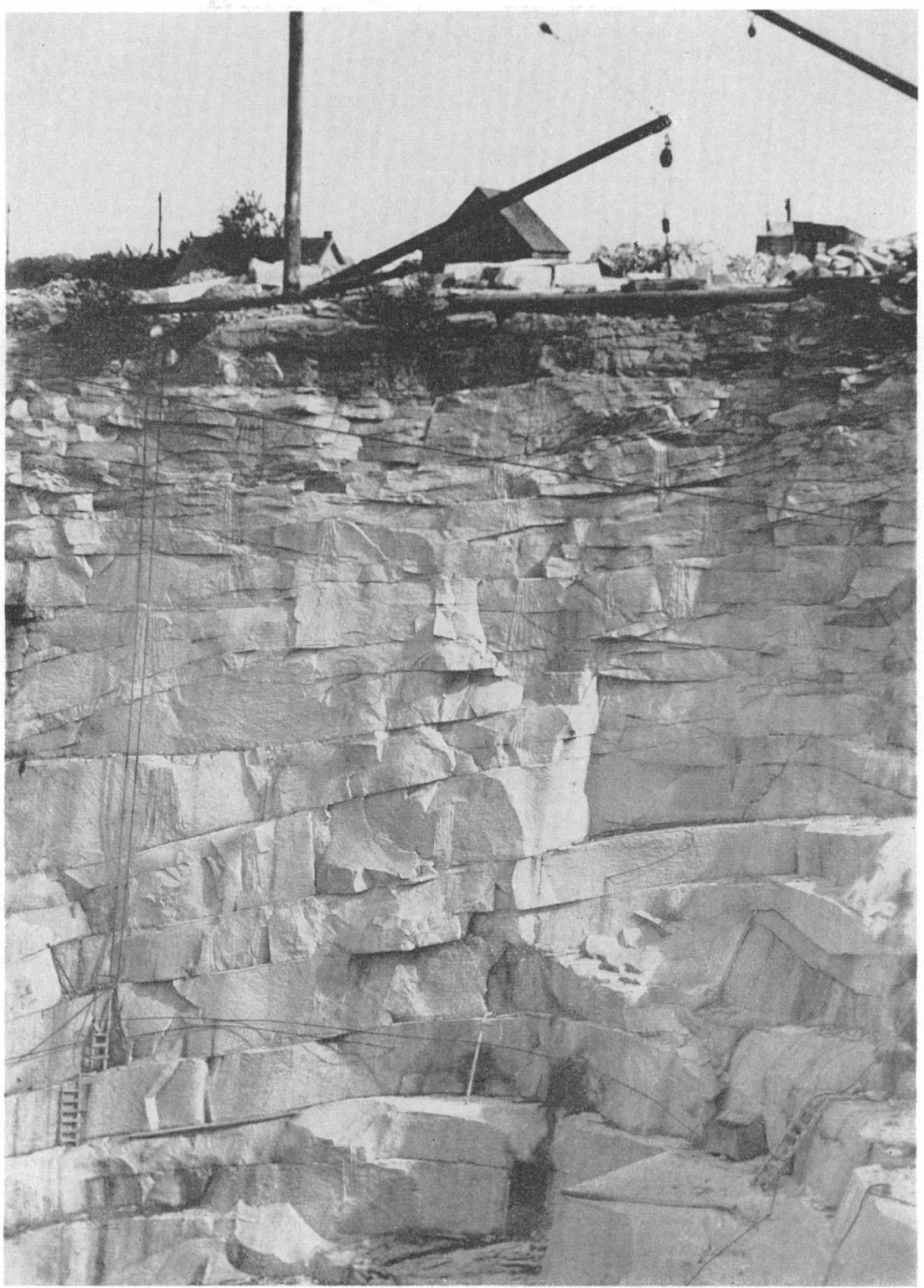

PIT QUARRY IN GRANITE SHOWING DEVELOPMENT OF LENTICULAR SHEETS Quarry is 100 feet deep. (After Dale, 1923, pl. 25A.) 


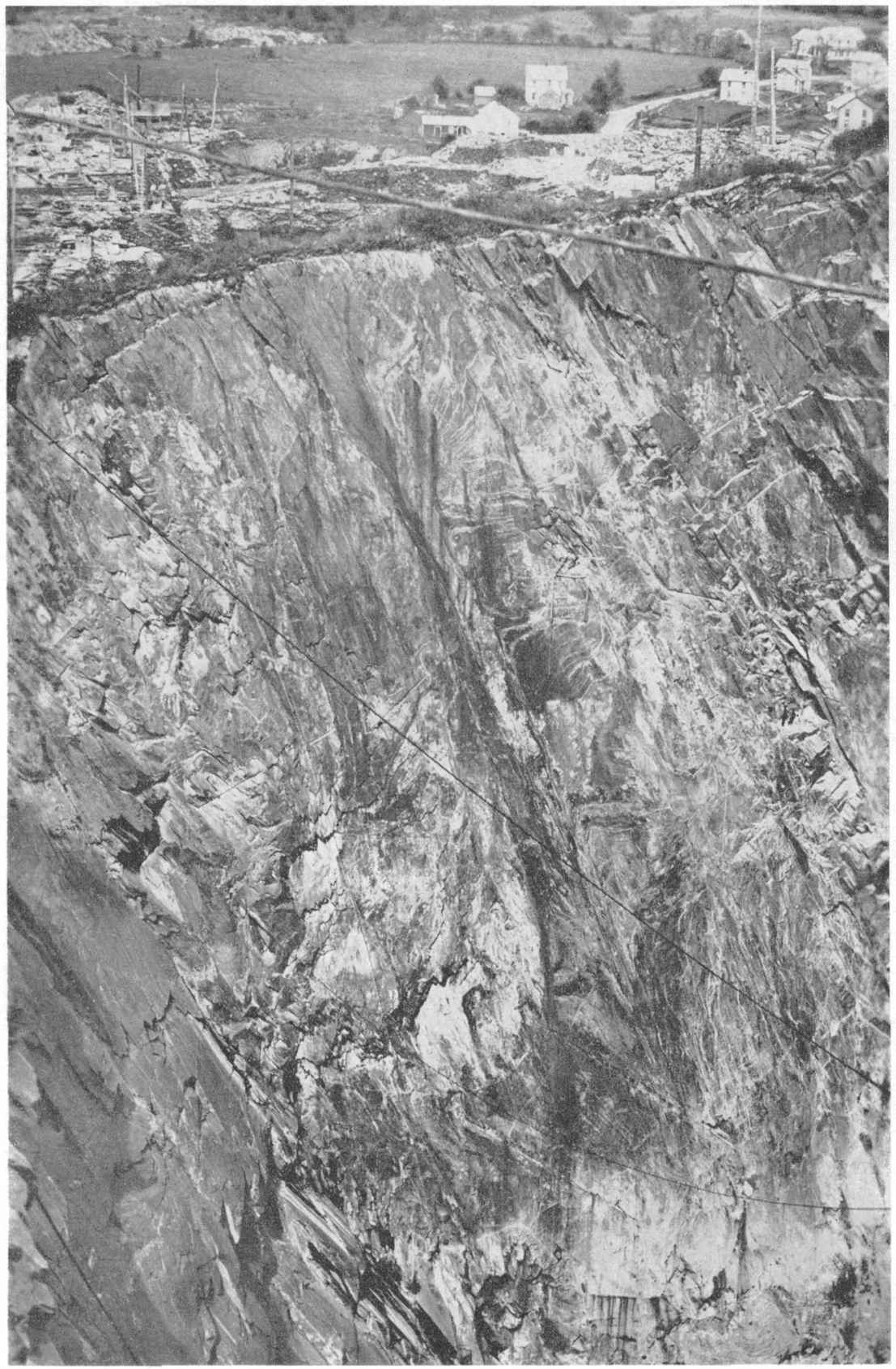

FACE IN SLATE QUARRY DEVELOPED ALONG BEDDING

Note slaty cleavage and joints in relation to closed (parallel limbed) folds. Quarry is in Vermont. (After Dale and others, 1914, pl. 25.) 
cellent primary cleavage are valueless for dimension sheets or blocks because of such features. Therefore, a very careful structural study of a slate deposit is indicated. In this connection it is helpful to remember that most slaty cleavage is approximately parallel with the axial planes of the major folds, whereas most secondary fracture cleavages develop at various angles to the axial planes.

A secondary direction of cleavage known as the grain is found in many slate deposits. This plane of cleavage (also called sculp or sculping by some quarrymen) is approximately at right angles to the slaty cleavage and parallel with the dip of this cleavage. Its intersection with the slaty cleavage is ordinarily manifested by striations, which, however, may be very obscure. It has considerable practical importance, for it permits dimension control of blocks from which thin slabs may be split and trimmed. Owing to the form in which structural slates are used-as thin sheets and slabs-the perfection of cleavage and grain and the absence of fracture cleavages are important qualities.

In the sedimentary rocks the rift is almost universally parallel with the bedding. Most quarries are in areas of approximately horizontal beds, so that the rift facilitates the development of benches. It also permits easy splitting within the usable beds and the freeing of usable from nonusable beds during the quarrying operations. Compact limestones, however, may not rift readily along the bedding direction. In markedly crossbedded formations, chiefly sandstones, rifting may be diverted along planes at angles to the major bedding. In sandstones the rift is generally more marked than in limestone. In some sandstone quarries (Ohio) grain is used instead of rift for the bedding cleavage. Ripple-marked sandstones give uneven rift surfaces that may require smoothing. Some sandstones. break easily across the bedding along tight, inconspicuous ("blind") seams or "cutters." Weathering sometimes renders "cutters" obvious, but others are discovered only as the stone is broken. Some "cutters" are extensive, others short and localized within a specific bed; they may be widely separated or they may occur in zones of closely spaced seams, rendering parts of the deposit worthless.

In most marble quarries the terms "rift" and "grain" are used" without distinction for the plane of easiest breaking. This is usually parallel with the bedding, but inasmuch as most marbles occur in regions of strong folding and metamorphism, the bedding is rarely horizontal and is commonly steeply inclined. Development of the quarry follows the favorable beds so that quarry openings may be long, narrow, deep, and overhanging; in some quarries underground quarrying is done by room-and-pillar methods. Obviously the geologist's study involves careful stratigraphic and structural mapping, and interpretative cross sections have particular value. By defini- 
tion, commercial marbles (see p. 72) include all crystalline rocks of predominant calcitic or dolomitic composition that are capable of taking a polish. Some crystalline limestones in essentially nonmetamorphic areas conform to this definition, and the geologic features pertinent to quarry development are similar to those of other sedimentary rocks and hence are less complicated structurally.

\section{VEINS AND DIKES}

Both veins and dikes are ordinarily objectionable for several reasons. First, they introduce foreign bodies that interrupt the continuity of the stone and so must be removed and disposed of, or avoided, in quarrying. Second, the spaces occupied by veins and dikes represent fracture systems, and their presence bespeaks dynamic disturbance of the rock mass that may be manifest by fractures that do not follow the regular joint systems. Third, associated alteration effects in the walls may penetrate rather deeply, involving a considerable volume of stone. Dikes, in particular, though presenting smooth and sharp contracts, commonly have caused thermal alteration effects in the wall rocks; the walls may also be shattered or sheared as a result. Veins are apt to be more objectionable than dikes because they are commonly more irregular, and many of them :are comparatively narrow and more numerous, so that their elimination involves rejection of much stone.

The nature, distribution, and continuity of veins should be carefully determined. Veins do not ordinarily permit practicable mapping on a quadrangle scale, but zones, if any, can be noted with respect to the commercial beds, major structural elements, and stratigraphic units. For rubble blocks, which are not shaped exactly to use, and riprap used for rough walls, small veins are not objectionable, but in mill blocks and mill stock (slate), or high quality ashlar they are objectionable. Even very thin and obscure veinlets provide seams along which blocks of otherwise sound stone may break readily, or fail under load. Veinlets, like hairline seams, may often be discovered by wetting a quarry face.

Stones containing veins are apt to weather unevenly owing to differential hardness or resistance between the vein and mass materials. Especially is this true of carbonate veins in siliceous rocks, or vice versa. Where the stone is used for interior finishes this weathering differential is not important, but differences in hardness of minerals promotes relief on polished surfaces. Indeed, some varieties of decorative stones, for example, verd antique marble, are valued for their veining; in these rocks, however, both the carbonates and serpentine minerals are comparatively soft minerals with slight differences in hardness, so that polishing to a uniformly smooth surface is possible. 
Veins in the sedimentary rocks are most commonly thin and composed of quartz or carbonate minerals. In some limestones, the veinlets are not apparent until the stone is worked or after it has been exposed to weathering, which, working along the contacts by solution and oxidation, produces weak zones and mars the finish Veins of quartz stand out in relief after comparatively short exposure to weathering. Conversely, calcite veins in sandstones weather out and pit or furrow the surface, promote absorption, and hence disintegration by frost action.

In marbles the common veinlike seams are mostly of two kinds"glass" seams and breccia fillings. "Glass" seams are joints that have been recemented by carbonates (chiefly calcite) or some form of silica (quartz or chalcedonic silica). Both kinds are undesirable because they constitute potential planes of breaking, but the siliceous are more objectionable because of their superior hardness, so that polishing to a perfectly smooth surface is very difficult. Siliceous seams, like knots of siliceous minerals, are sufficient cause for rejection of the stone for decorative purposes. Carbonate seams, however, though they make the stone structurally unsound for exterior purposes or where considerable load is applied, may enhance the decorative value for polished slabs, wainscotting, etc. Besides verd antique, serpentine marble, which is characterized by many veinlets of carbonate minerals, marble breccias cemented by calcite furnish some of the most desired decorative stones.

In granites the veins commonly present include aplites, pegmatites, and quartz veins. In some granites these are very abundant, in others they are remarkably few (for example, Barre, Vt.). Pegmatites range from large lenses or wide veins that may traverse the quarry to mere knots or vuggy "blobs" a few inches in maximum dimension.

In slates, veins are common and are particularly injurious. Whether they follow or cross structural planes they render the stone worthless by preventing cleavage into smooth and thin sheets; as well as by promoting weathering. Quartz (flint) and carbonate (spar) veins are most common. A group of quartz veinlets in fracture zones: of slate is illustrated in plate 6 .

\section{INCLUSIONS AND SEGREGATIONS}

Inclusions and segregations of other rock types, or crystals and aggregates of minerals not normally constituents of the rock species, are ordinarily detrimental to the commercial stone. For the most part, where such are present in abundance the quarried blocks are suitable only for use as riprap or fill. Veins and dikes belong broarlly in this category, but they have been considered separately because they are relatively large, distinctive in shape and structural relations, and can ordinarily be avoided or rejected in quarrying. In- 
clusions and segregations, on the other hand, are comparatively small masses within blocks of commercial stone and often cannot be discovered until mill blocks have been split for shaping and finishing, so that their rejection entails considerable cost.

In the crystalline rocks, granites and marbles, inclusions are generally remnants of other rock types, as breccia fragments, blocks, lenses, etc. Lenses and septa of schists and slaty rocks are common types 'of inclusions in both marbles and granites. - In marbles and in some granite gneisses these generally represent interbeds of an original sedimentary sequence, and so may be complexly infolded or sheared and more or less restricted to certain stratigraphic horizons. In granites they generally represent undisplaced or unreplaced fragments of country rocks. In metasomatic granites (so-called granitized rocks) they display various forms, ranging from but slightly replaced inclusions or beds with fairly sharp contacts to streaks and mere wisps that fade out into essentially uniform gneissic granites. With respect to metasomatic granites it is pertinent to note that the distribution, foliations, and attitudes of such remnants are generally consistent : with the general "foliation and relict "ghost": structures of the granites, as well as with the foliations and attitudes of the surrounding country rock.

Some granite stocks possess relatively basic border zones, but these may not disqualify the granite as a structural stone. However, the border stone is apt to contain more inclusions of country rocks than are the interior portions. Border zones of migmatitic or replacement granites, on the other hand, generally contain much partly replaced wall-rock material, most commonly of biotitic schist, and are far from uniform in composition and texture, grading from the gneissic granite of the main body of rock through granitic gneiss into schist.

A comparatively rare type of granitic rock is the orbicular granite, such as those at Craftsbury and Bethel, Vt., and in Davis County, N.C. In these Vermont granites, the orbicules are ovoidal segregations, composed chiefly of biotite, and usually less 2 inches in maximum dimension. Where abundant and more or less uniformly dispersed, the orbicules render the stone unsuitable for major structural use, but where present in very small amount and dispersed, as in the Bethel granite, they are not particularly objectionable for they do not impair the integrity of the stone, and blocks may be split with little rejection.

In sedimentary rocks rejection of noncommercial stone is made ordinarily by layers, certain beds of the sequence being unsuitable. Such interbeds or partings can scarcely be considered as inclusions in the sense described above, for they are stratigraphic members and, hence, are continuous. They may be discarded in quarrying. Nevertheless, their removal and disposal add materially to operating costs. 


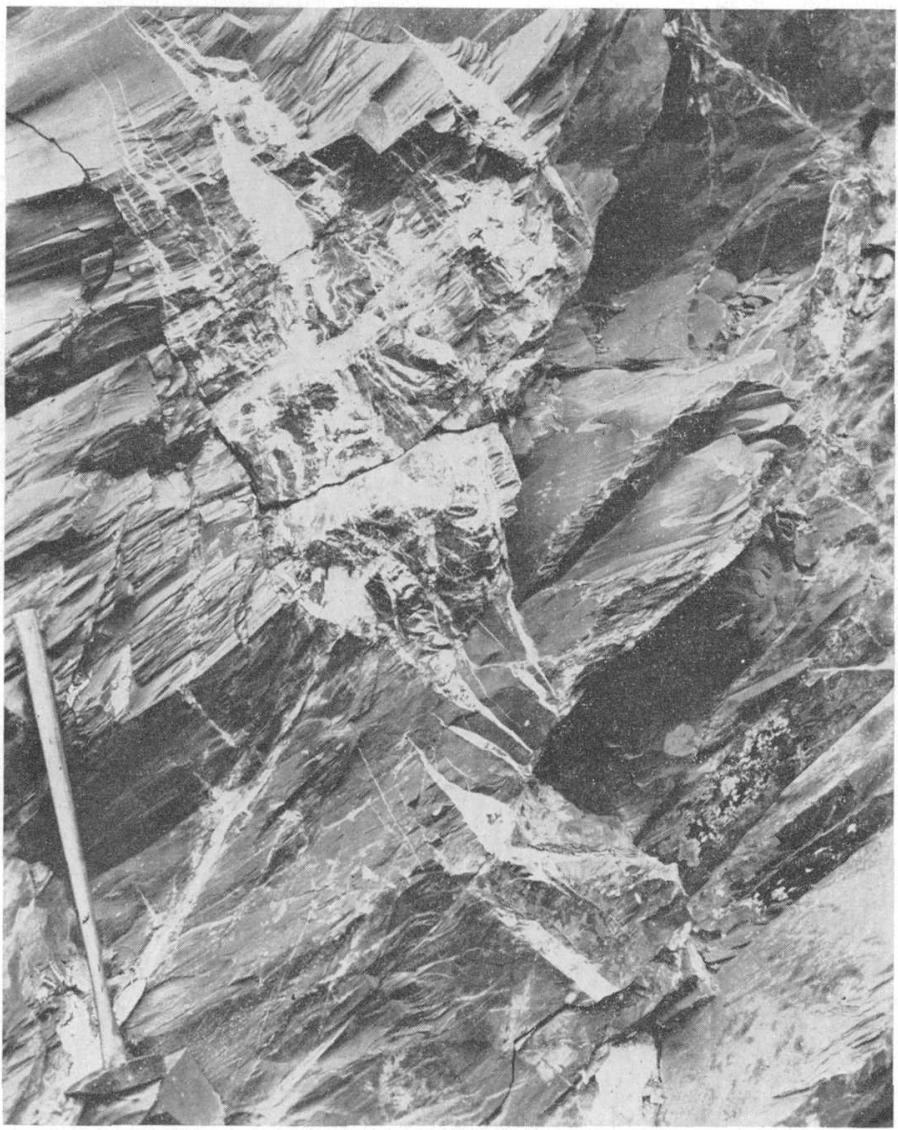

ZONE OF QUARTZ VEINLETS CROSSING CLEAVAGE OF SLATE

Veinlets are in shatter zone. (After Dale and others, 1914, pl. 5A.) 


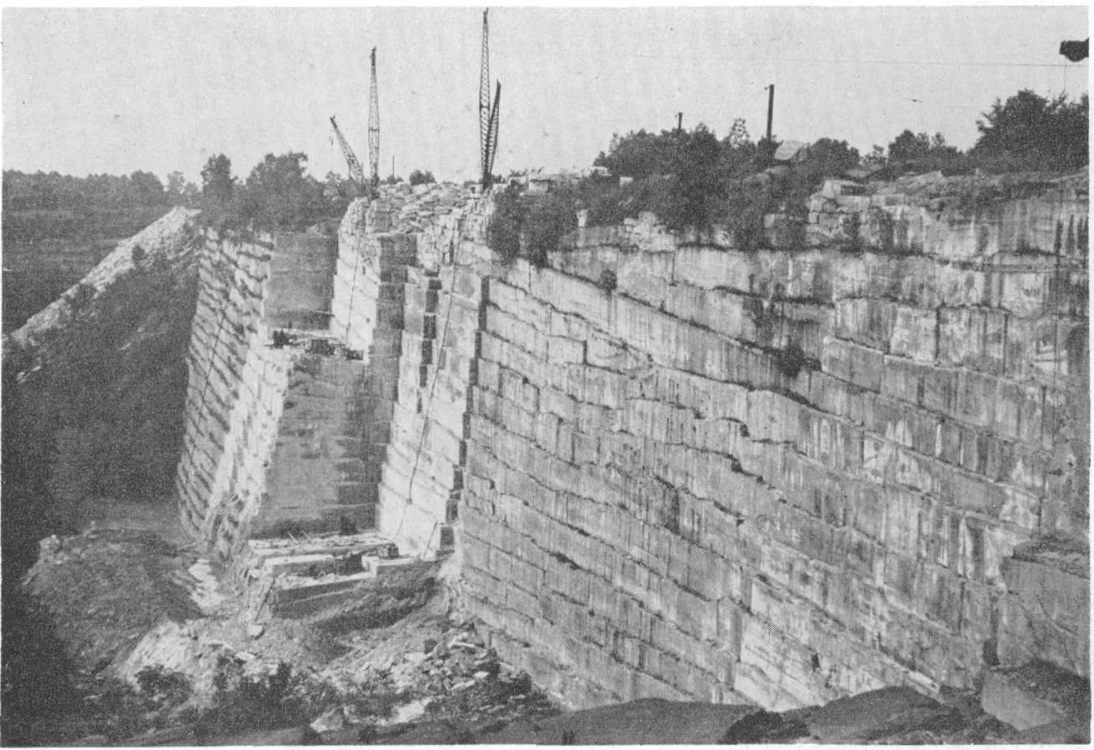

A. PIT QUARRY IN HORIZONTALLY BEDDED SANDSTONE

Pit quarry, 200 feet deep, in Berea sandstone (Ohio) showing mode of development by splitting, sawing, or channeling horizontal beds on benches. Owing to original deposition of Berea sand in channels (channel sandstone) cut into underlying shale, the thickness of the commercial sandstone changes abruptly; drilling at a point 300 feet from the quarry wall penetrated only the underlying formation. Smooth rock surface, with thin overburden of glacial drift. (After Pepper and others, 1954, fig. 14.)

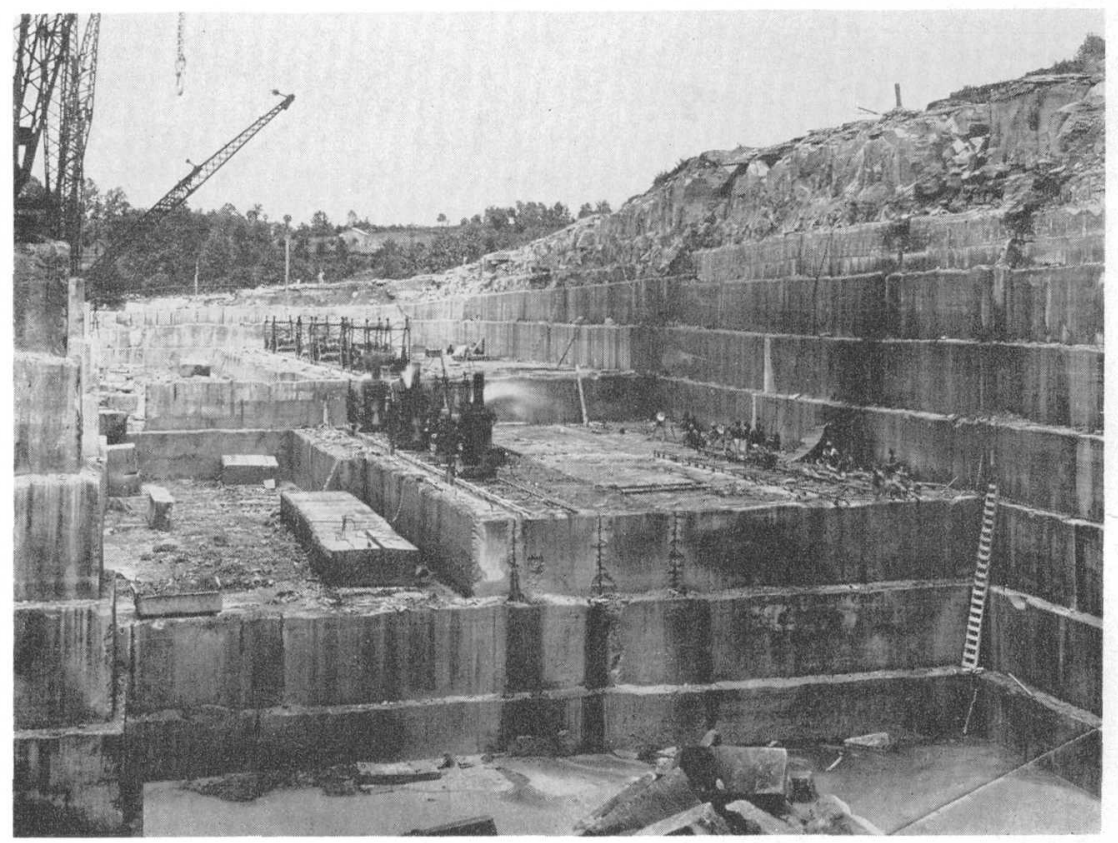

B. PIT QUARRY IN HORIZONTALLY BEDDED LIMESTONE

Pit quarry (Bedford, Ind.) showing method of development by benches. Overburden of thin glacial drift and thin-bedded noncommercial stone. (After Loughlin, 1929, pl. 40B.) 
The mode of quarry development and operation can, however, be planned in advance with respect to them.

In limestones, knots or nodules of silica-as quartz, flint, or chert - or of siliceous minerals are objectionable. They do not work down easily to finish surfaces, because of their superior hardness. Their contacts are not well integrated with the limestone mass, and inasmuch as they commonly occur along certain layers they may cause the stone to split. Bedding layers of chert may also facilitate frost action. Some limestones contain crystals or nodules of pyrite or marcasite, which oxidize readily to cause unsightly stains and local decomposition of the stone owing to the formation of acids.

Sandstones and quartzites are generally more free of objectionable inclusions, except partings, than are other sedimentary rocks. As a class they show greater stratigraphic variation, so that thin partings of shaly or schistose character may cause rejection of certain beds of a sequence. Clay partings may be particularly harmful, not only because of their structural weakness, but also because they may absorb considerable water. Concentrations of secondary iron minerals as bedding streaks and nodules are found in the more porous layers; for the most part these are due to deposition from ground waters circulating in the oxidizing zone and may be absent from deeper beds. In some rocks they arise from oxidation of pyrite and other iron minerals. Where the cementing material is silica such limonitic istreaks are not necessarily harmful, for the limonite may merely fill pores and act as a cementing matrix. Indeed, some sandstones of this nature are prized for their decorative value. Limonitic nodules, however, are objectionable because they disfigure or weaken the stone and do not drêss: well to a finished surface.

Some sandstones contain excessive amounts of mica flakes, mostly segregated in certain layers, and in sufficient concentration to cause the stone to break or flake during quarrying or, milling, or subsequently when in use. (See discussion of "Weathering," p. 59.) Some sandstones and limestones also contain petroleum or petroleum tars, harmless insofar as integrity of the stone is concerned but highly objectionable in building and monumental stones because of the unsightly stains caused by these substances.

Many slates contain large crystals or nodular masses of metamorphic or metasomatic minerals, such as staurolite, garnet, andalusite, etc., pyrite or marcasite, and ferriferous carbonates. These are always objectionable because they prevent smooth splitting, weaken the stone, or promote weathering and staining. Nodules of quartz or chert are not uncommon and make it difficult to work the slate into satisfactory finished forms. Electrical slates (slates used for electric switchboards and panels) must have a very high dielectric constant, so that graphitic carbon, either in microscopic dis- 
seminated flakes or in localized concentrations is to be avoided in slates to be used for electrical purposes. By the same token magnetite in similar forms is objectionable.

\section{OVERBURDEN}

In its broadest sense, overburden includes all material that must be removed from the surface down to commercial stone. This embraces the unconsolidated surficial deposits-soil, sand, gravel, till, etc.-and top layers of worthless rock. In practice, however; the term is generally applied only to the unconsolidated materials, for the weathered or noncommercial underlying rock must be removed by regular quarry operations, whereas the loose materials are handled by simpler methods. Moreover, in many quarries the upper layers of rock, if not appreciably weathered or of shaly character, may furnish a byproduct of crushed stone.

It is important to record the nature and thickness of the overburden, for the cost of removal and disposal constitute an appreciable economic item in the overall quarry operations. In some instances such costs have determined the economic feasibility of development. Methods of removal and disposal for a large quarry operation must be planned carefully by the operator and projected to allow for expansion during the life of the quarry.

The nature of the contact between the overburden and the commercial stone is also important. If the contact is sharp and relatively smooth the rock surface may be easily stripped bare; if sharp, but uneven, the process of stripping is more costly, for projections or pinnacles of rock interfere with simple stripping methods and must be removed later by quarrying techniques. If the contact is gradational, as by deep secular weathering of the noncalcareous rocks, a combination of methods is involved, and stripping involves removal of some partly weathered rock material as well, in order to expose unaltered commercial stone. In unglaciated areas underlain by calcareous rocks (limestone and marble), the contacts between bedrock and unconsolidated cover are generally sharp but are very irregular owing to the presence of pinnacles of undissolved rock; here the overburden is composed ordinarily of residual clay.

In glaciated areas, such as New England, the overburden consists of glacial drift, mostly till (heterogeneous and unsorted mixture of materials ranging from boulders to clay sizes), less commonly glaciofluvial or glaciolacustrine gravel, sand, silt, or clay. The contacts with the bedrock are sharp and relatively smooth, for the preglacial weathered zones and original residual soils have generally been scraped off by glacial action. Very large boulders, of course, require blasting, adding materially to the cost of stripping; the concentration 
of boulders is, then, another geologic factor in the development of a stone deposit in glaciated terranes.

Thin overburden of soil materials may be stripped off by dragline or by hydraulic methods; thicker overburden will require a power shovel, perhaps supplemented by blasting of worthless rock material. Observations on the nature and thickness of the overburden are consequently of considerable economic importance to the operator in planning the opening or expansion of a quarry.

The continuation of deposits beneath areas covered entirely by unconsolidated materials, such as residual soils, alluvium, and glacial sand, gravel, and till, is predictable from a geologic map, even though outcrops are wanting. This is largely a matter of interpretation by the geologist, but may be of material aid in exploring for extension of operations into areas of favorable topographic position.

\section{WEATERERING}

The durability of a dimension stone in structures not subjected to abrasive wear is determined chiefly by resistance of the stone to disintegration by weathering processes. The problem of estimating this resistance is not easily resolved, as was pointed out under the section on durability (p. 36), where the salt crystallization test was discussed. It is probable that a stone which can withstand the rigors of a salt crystallization test can easily withstand frost action. The converse, however, appears to find little confirmation in actual data. Judgment of the comparative weathering properties of stones remains, in large measure, qualitative and a matter of observation of stones both in place and in use.

Several factors besides frost action influence the resistance of a stone to weathering. These are both constitutional and environmental. Constitutionally the mineral composition determines the path of chemical alteration under weathering, but the rate of such change is influenced by the environment. Moreover, the natural environment of the rock promotes mineralogic alterations that may be prominent in outcrops but inconsequential for the stone in use. Soil waters, seeping atmospheric waters, and ground waters cause obvious chemical changes that indicate the natural susceptibilities of the stone and the paths of alteration. Under ordinary conditions of use above ground in an artificial structure these agencies are not at work so that their combined effects through geologic time are not felt by the stone in use. Where the structure extends below ground or capillarity brings soil water into the base courses, these agencies may act; however, the important time factor is lacking, so that the rate and intensity of chemical alteration are not comparable with those affecting the rock in natural position. Nevertheless, the inherent weaknesses and susceptibilities of the stone and the potential paths 
of weathering are indicated by the mineralogic and physical changes that have taken place in outcrops. Recording of these natural weathering effects is, therefore, of some importance, particularly if the weathered rock can be compared with rock obtained from below the zone of weathering, as in abandoned quarries or long exposed old quarry faces. Natural weathering may bring to light the presence of detrimental minerals or of otherwise obscure geologic weaknesses of structural nature. These the geologist may point out even though he may not be able to translate them into quantitative terms of durability.

\section{Physical Weathering}

Physical weathering is a mechanical process of disintegration brought about by cycles of temperature changes. In part, it is due to expansion and contraction of mineral grains and, in part, to frost action through the alternate freezing and thawing of water contained in pores, seams, and fissures.

The various common rock-forming crystalline minerals not only possess different coefficients of expansion, but individually they expand and contract differentially according to crystallographic directions. As a result, where the temperature range is relatively great the texture is loosened, and ultimately there is a spalling of the rock to give a loose granular material composed of the original minerals. Thus stones exposed in arid or semiarid regions disintegrate largely by this process. However, it is essentially a surface or "skin" phenomenon, for rocks are poor conductors of heat and the temperature differential is felt but slightly a few feet below the surface. In the course of geologic time the process is very effective in promoting disintgration, but the effects on stone in ordinary structural use are generally inconsequential. In such regions, therefore, a stone deposit is not to be condemned because of obvious mechanical disintegration at the surface.

Far more disastrous are the effects of frost action in humid regions even where the temperature range is much less than it is in some dry regions, provided, of course, that temperatures range from above to below the freezing point of the pore water. Here again, the phenomenon is effective only to shallow depths in the rock. The resulting exfoliation rather quickly exposes new layers to the same destructive effects of frost. Stones with pores of capillary size or greater will be thus affected by frost action unless the pores are large enough to permit ready draining of the pore waters. Thus some very porous stones of clastic texture are particularly prone to exfoliate under frost action; if they are markedly stratified, and particularly if the beds are thin, the spalling due to frost action may be very rapid, especially if the blocks of stone are set on edge instead of "on bed." Notable examples of these are the famous "brown- 
stones" of Triassic age formerly quarried extensively in a belt extending from Virginia into the Connecticut Valley of Massachusetts. Careful examination of outcrops and of old quarry faces will generally disclose the susceptibility to frost action and may bring to light otherwise obscure minor structural deficiencies of the rock. It should be borne in mind, however, that disruption by frost action is rarely as intense in stone that has been processed and placed in structures as in outcrops that have been exposed for a long period of time. Construction blocks properly drained, seasoned, and set have much less opportunity to absorb moisture than does stone in the quarry, subjected as it is to saturation by seeping and ground waters.

\section{Chemical weathering}

Sulfide minerals, most commonly pyrite and marcasite, are usually considered to be among the most deleterious minerals for any building or monumental stone. Their oxidation forms the hydrous oxide of iron (limonite), sulfurous and sulfuric acids, and, at times, sulfates of iron. The acids in turn readily attack the common carbonate minerals, calcite and dolomite, to form soluble sulfates that may crystallize within the pores and so promote mechanical disruption through the force of crystallization. Even in noncarbonate rocks the acids attack various silicate minerals, though much more slowly, and weaken the rock by loosening its texture. Even though they may not materially weaken an exterior stone through their oxidation, they are prone to cause unsightly rusty spots and streaks. However, a few scattered grains of pyrite are not necessarily to be considered sufficient reason to reject a stone-much depends upon the distribution, on sizes of grains of the minerals, on the porosity and, of course, on the way in which the stone is used. Pyrite appears in very small amounts in some excellent commercial stones of low porosity and remains fresh for many years. Finely divided pyrite is generally much.more susceptible to rapid weathering than are the larger, obvious crystals. The texture of the stone, too, influences the rate at which pyrite will oxidize. Scattered grains that are clearly visible to the unaided eye may have no serious effect upon the integrity of a stone of very tight texture, such as granite. Pyrite polishes readily and does no harm ordinarily in polished stone surfaces for interior finishes.

In sandstones with calcareous cement, limestones, and marbles, oxidizable pyrite may be harmful not only because of staining but because the acids formed by oxidation rapidly attack the carbonate minerals, rendering the stone more porous and texturally weaker. However, that small amounts of oxidizable disseminated microscopic pyrite grains are not necessarily harmful, even in fairly porous stones, is exemplified notably by the Indiana oolitic lime- 
stone. This stone is reported to contain a small amount of disseminated minute grains, oxidation of which contributes to the coloring of the stone, but the amount of the mineral is too small to be detrimental; analyses of gray and buff limestones show ferrous oxide up to 0.07 percent, representing pyrite up to approximately 0.10 percent (Loughlin, 1929, p. 147).

In the fine-textured noncalcareous Berea sandstone of Ohio, minute grains of pyrite are disseminated rather uniformly; their oxidation not only causes a uniform and pleasing color change but "may result in positive good by supplying a cement to the individual grains" (Weidman, 1942).

Marcasite is much more easily oxidized than is pyrite and is always objectionable in a commercial stone. It is confined practically to sedimentary rocks, because it is deposited at shallow depths from low temperature acidic solutions and is commonly associated with organic environments.

Much more rarely than pyrite and marcasite, other metallic sulfides are found in dimension stones, as, for example, sphalerite in the Yule marble (Yule limestone of former usage) of Colorado. Sphalerite contains variable amounts of ferrous iron, substituting for zinc, and is subject to comparatively easy oxidation by which, as with pyrite, sulfuric acid is formed. In carbonate rocks this acid further attacks the calcite and dolomite, while oxidation of the iron produces limonite stains.

In the study of ore deposits it appears that sulfides of the common metals oxidize in the following order, that of zinc (sphalerite) being most readily oxidized: zinc, copper, iron, and lead. Thus, fresh pyrite may persist in a rock in which the sulfides of zinc and copper have been materially altered. Inasmuch as oxidation of all the metallic sulfides yields the objectionable sulfuric acid, any dimension stone that contains sulfide minerals should be examined critically for evidences of oxidation, such as staining of the stone, increased porosity in the vicinity of sulfide grains, and limonite coatings of the grains. Microscopic study of thin sections or polished surfaces is recommended, especially for the limestones and marbles. Any sulfide that has remained fresh within the quarrying depths will probably remain fresh when the stone is in normal use, except where unusual atmospheric and environmental conditions exist, such as attack by smoke and industrial fumes or capillary rise of acidic soil waters.

Carbonate rocks of the limestone group, more especially the dolomitic rocks, are apt to contain the easily oxidizable ferrous iron, which substitutes for $\mathrm{Ca}$ and $\mathrm{Mg}$ in the carbonate molecule. Even if present only in very small amount, this iron may oxidize easily and impart a buff tint to the stone without materially affecting its 
integrity. For many years the Niagara dolomite in the Chicago and Joliet, Ill., areas was quarried for building stone; much of this material weathered to a buff color after use, owing to the presence of iron both as carbonate and as sulfide.

Magnetite is common in both crystalline rocks and clastic sedimentary rocks and is an easily oxidized mineral. It is a common minor accessory, generally microscopic, constituent of the crystalline rocks. As microscopic grains in these rocks it is not objectionable; megascopic grains, however, oxidize readily to make unsightly stains. In the porous sandstones, the clastic grains of magnetite may be comparatively large and weather rapidly to cause spots and streaks of limonite, though the mineral has no appreciable chemical effect in promoting disintegration. Some of the "black granites". (see p. 71) contain larger amounts of magnetite than do the other crystalline rocks, but the mineral polishes fairly well and a small amount is not ordinarily objectionable in stones for interior use; in exterior panels of these stones the mineral will weather readily and produce unsightly stains.

The concentration of iron stains along sedimentary layers of porous rocks is not necessarily indicative of chemical weathering of the rock. Particularly in sandstones it may be due to deposition of oxidized iron from ground-water solutions that find easier paths of flow along the more porous, coarser textured layers. In these the secondary iron hydroxide minerals, mostly limonite, act also as a cementing material. Some sandstones showing this condition are particularly prized for their decorative color effects.

Muscovite is generally stable, and insofar as chemical weathering is concerned this mineral rarely shows any alteration. It may become discolored, however, through penetration by limonite between folia, so that such discoloration should stimulate careful examination of the stone for alteration of other iron-bearing minerals and for mechanical effects of frost on thick crystals of the micas.

Biotite is apparently much more susceptible to chemical weathering than is muscovite. However, different varieties of the mineral behave differently in this respect: Some biotites bleach readily or assume a bronze coloration. Some are partly or wholly altered to chlorite, but this change is due probably to some form of thermal or hydrothermal alteration rather than to weathering and so offers no clue as to the weathering resistance of the stone. For the most part biotite remains fresh in building stones, even when outcrops display appreciable weathering of the mineral. In tight-textured stones, such as the commercial granites, biotite ordinarily remains fresh even in long continued use; indeed, the majority of the successful granites contain biotite as a prominent accessory mineral. Nevertheless, where biotite shows signs of weathering in exposures, 
a petrographic study of the rock is desirable to determine other effects of weathering within the rock.

The ferriferous varieties of amphiboles, chiefly the hornblendes, weather quite readily under natural environments, forming limonite, carbonates of calcium and magnesium, and clay minerals. Like biotites, however, the unaltered hornblendes in stone obtained from below the zone of weathering remain fresh in structural stones of tight texture, and many successful commercial granites in long use contain hornblende as a prominent constituent. Nonferriferous varieties of amphibole, chiefly tremolite, and of pyroxene, chiefly diopside, occur commonly in marbles and are susceptible to fairly rapid weathering; the alteration is due, in part, to the effect of carbon dioxide and, in part, to oxidation of the very small amount of iron that is commonly present. Outcrops and quarry faces of marbles should be examined closely for the presence, abundance, size, and distribution of tremolite and diopside crystals and for evidence of incipient alteration; in such alteration the crystals lose their luster, and become chalky and soft, making it impossible to impart uniform polish to the stone.

The feldspars, occurring chiefly as essential constituents of commercial granites, are readily, though slowly, altered in nature by the action of soil and ground waters containing carbon dioxide. However, below the zone in which such agencies have been active, the feldspars remain fresh and also undergo no appreciable alteration in dimension stones in use. Two types of alteration of feldspars are common in granites. One is the common weathering to clay minerals and is largely an interstitial phenomenon; the other is the more penetrative sericitization, in evidence along cleavages and other crystallographic directions when the rock is examined petrographically. Sericitization may be obvious in a granite without being pronounced enough to affect the integrity and durability of the stone; consequently, the clouded grains and phenocrysts of feldspars in some commercial granites are not detrimental. (Example: granite from Deer Island, Maine.)

In general, it may be stated that alterations by which limonite and clay minerals are formed are detrimental to a stone. Alterations that result in a minor amount of sericitization, chloritization, or epidotization may be harmless; indeed, in some instances they have enhanced the decorative value of a stone by virtue of their color effects. A petrographic examination will serve to determine the extent to which such alterations may be tolerated, that is, whether or not the textural integrity of the stone has been impaired.

In nonglaciated regions chemical decay through long periods of time has commonly left a thick residual layer of soil that grades into the underlying bedrock. For humid temperate regions the processes of chemical decay-chiefly oxidation and hydration, with 
attendant leaching of carbonate minerals-are more deeply penetrative than purely mechanical processes due to temperature changes. Consequently, the transition from soil to solid rock is so gradual that incipient chemical weathering may remain undetected well into the apparently solid rock. Microscopic examination is, therefore, indicated. Stripping of overburden in such areas may be difficult and involve much solid rock material. In many places the combined 'soil and partly weathered layer is too thick for economical stripping operations. It is not possible to state economic limits, for each deposit is an economic problem in itself. However, the geologist can offer pertinent data as to the thickness of the weathered zone, the nature of the weathering processes that have acted upon the rock, and microscopic evidences of alteration. Limestones and marbles present a special aspect. With them the principal process of weathering is a leaching of the carbonate minerals-the principal constituents of the rock-because of their ready solution in soil waters containing acids and carbon dioxide. The common impurities of such rocks are minerals of the clay group, silica as chert, and, in certain marbles, silicates of lime, magnesia, and iron that alter easily. The resultant residual soil is commonly a red or orange clay, and, unlike other rock types in nonglaciated areas, it has a sharp contact with the underlying rock. However, though sharp, the contact may be very irregular owing to pinnacles of the undissolved bedrock. Recognition of a pinnacle and cave terrane is, of course, within the field geologist's scope and is very important to the prospective operator.

In glaciated regions, on the other hand, the preglacial products of chemical decay as well as projections of partly weathered bedrock have usually been swept more or less cleanly away and new deposits of glacial origin deposited in their places. Thus a glaciated area commonly displays smooth and rounded fresh surfaces of bedrock, with covering deposits of till, boulders, gravels, sand, etc., derived from other areas. The cover of glacial soils-till and outwash sediments-lies in sharp, smooth contact with relatively fresh rock or on a thin zone of slightly weathered material, a condition that favors effective and economical stripping of the deposit.

Ordinarily, the weathering of rocks in a glaciated region has been restricted to a comparatively brief period of geologic time, in many places not more than a few thousand of years. Consequently, even in exposures the potential commercial stones may be practically fresh at a very shallow depth, so far as mineral alterations of a chemical nature are concerned. However, mechanical effects due to temperature changes, chiefly frost action, may be pronounced close to the surface, having started under periglacial climatic conditions as soon as the glacial ice left the area. Such action, too, often brings to view inherent structural and textural weaknesses. 


\section{INDUSTRIAL, FEATURES}

\section{CLAssification}

The standard classification of the American Society for Testing Materials (see p. 70) may be used. The designation under this classification may be expanded by emphasizing particular compositional and textural qualities through the use of varietal terms commonly used by geologists, as thinly bedded micaceous sandstone, argillaceous limestone, coarse-grained hornblende granite, dolomitemarble, granite gneiss, and micaceous quartzite, etc. The terminology used, however, should be free of jargon and sufficiently nontechnical to be readily understood by the nongeologist who, nevertheless, has access to the standard ASTM classification or to standard dictionary definitions. In other words, the purpose of an industrial classification should be to use lithologic terms of common understanding within the stone industry and the engineering and architectural professions. More technical aspects and terminology are left to the petrographic description (p. 46) which is primarily for use by geologists and petrographers.

\section{USE OF THE STONE}

Under this heading may be indicated the category given under "Classification by uses" (p. 7), augmented by specific sales uses as provided by the quarry operator. Mention might be made of qualities that befit the stone particularly for special uses, such as ornamental, statuary, interior finish, and the like.

For undeveloped stones the geologist might suggest possible uses in broad terms as building stone; monumental, etc., on the basis of general criteria.

\section{TOPOGRAPHY}

The topography of the area involved is of importance in the development of new quarries. Hillside openings (shelf quarries; pl. 2) facilitate access to the quarry and removal of stone with a minimum of hoisting expense. In places, they permit quicker development of the deeper stone. Hillside development also minimizes drainage problems. Waste may be disposed of without interfering with areas of future development. Such quarries require, of course, adequate front acreage for the construction and operation of storage sheds and mills, for location of waste (grout) piles, and for access roads. In areas of low relief, some of these advantages may be partly lost by ultimate development below the quarry floor to reach deeper beds. Moderate development below the floor level, however, will permit access inclines for operation of trucks.

In flat areas or areas of very low relief, pit quarries (pls. 4, 7) are required. Here, of course, initial development is primarily a 
vertical operation until desirable beds are reached; thenceforth, lateral development is dominant so long as quality stone is available within property limits. Lateral development must be planned ahead not only by prospecting of the peripheral area, but also with respect to surface plants, storage yards, and waste disposal. Removal of stone from deep quarries by hoisting is relatively costly, and the horizontal development of shallow quarries with broad benches at several levels may permit truck and railroad inclines.

Thus data on the topography, relief, and drainage of a prospectable area are pertinent to the geologic appraisal of a stone deposit.

\section{ACCESSIBILITY}

Note should be made of the geographic position of the deposit or quarry with respect to railroad lines, improved highways, and access roads. Local markets are served by truck haulage, distant markets by rail or ships. In either case adequate access roads must be built and maintained, for trucks constitute the primary medium of transportation from the quarry to the siding or wharf. Many deposits of high quality stone are found to be commercially worthless because of high transportation costs, beginning even at the quarry. For undeveloped deposits, access roads or need for building them are items in the overall appraisal. The field geologist is concerned with the topography as related to access roads and the remoteness of the deposit as related to transportation facilities to markets. The consultant should carry the study further with preparation of a largescale topographic map of the proposed quarry site and with judgments as to locations of possible access routes.

\section{OPERATING FACILITY}

Under this item are to be pointed out briefly the structural elements and cleavage properties that appear to favor opening and economic development of the deposit. For undeveloped deposits it is, of course, based on the judgment of the field geologist and serves merely to guide further prospecting and exploration. It would be pertinent, moreover, to indicate parts of deposits or areas that are most favorable. In effect it epitomizes the major geologic, geographic, and topographic features that are described in more detail under preceding topics. The consultant will need to indicate reserve areas for future development and possible sites of plants and quarry wastes.

\section{WORKABILITY OF THE STONE}

Data on workability of the quarry blocks into finished products are obtainable only from operations in active quarries and plants or by actual testing of blocks. Projection of workability properties to undeveloped parts of a deposit or district, then, becomes a matter 
of judgment based on field evidences of uniformity of the deposit.

For the crystalline rocks workability of the stone will vary, often markedly, with texture and composition. For the stratified rocks workability is also influenced by lithologic and structural variations both across and along the bedding and by variations in porosity.

Workability of stones, in general, is influenced by the amount of "quarry water," that is, water contained in pores of the rock as quarried. The more porous rocks, particularly the sandstones, of course, contain the largest amounts of quarry water. The quarry water sometimes interferes with quarrying in freezing weather. Moreover, inasmuch as quarry water is actually a solution containing mineral substances, especially silica and lime carbonates, evaporation of the water as it seeps to the surface commonly results in "case-hardening". of the stone by deposition of silica in the pores; this may make dressing of the stone more difficult. Some stones, therefore, are more easily dressed when freshly quarried. The crystalline rocks are less affected, in general, by this process; nevertheless, some of these are appreciably hardened in the surface layers by such "seasoning." Clearly, not only the percentage porosity but the sizes of pores affect the seasoning effects, either by capillary retention or by ready draining of contained water, as indicated above, under "Texture and fabric" (p.47).

\section{CoIOR}

The subject of color has been previously discussed in a general way in pages 33 to 36 . Little more need be recorded here, except that the industrial designation of color is largely a matter of the producer's marketing practice-sometimes tempered with a fairly generous admixture of his imagination. Trade names are commonly based on the general color effect of the stone, as "Kasota pink" (a dolomitic limestone), "Chelmsford white" (a granite), "Rockport green" (a granite), "St. Albans red" (a marble), "unfading green" (a slate), and the like. Such designations are well known and understood in the trade, but they hardly serve to give an accurate idea of the true color of the stone. Some "white" stones are light gray, owing to admixture of prevailing white mineral and subordinate black; others are uniformly white.

Unfortunately, the trade has not established standard color specifications for any class of stone, except, in a general way, for slates. Nor have standard specifications been established for an accurate measure of color or shade. For undeveloped deposits, however, and for more specific descriptions of the products of active quarries, the prevailing color in hand specimen or freshly exposed rock surface may be stated, together with the trade designation, if any. 


\section{RESERVES}

For purposes of general mapping the field geologist need indicate the inferred resources of stone only in a very general way. His statement will indicate, first, the existence of apparently favorable stone deposits, and second, the inferred resources as a guide to consideration of the deposits for more specific quantitative and qualitative estimation by the consulting geologist or operator. The extent to which resources are so inferred depends, on details of field data, time at the geologist's disposal, present industrial importance, and indicated objectives of the mapping project. According to his discretion and directives, his statement may range from a simple general qualitative statement to broadly approximate quantitative measures based on areal distribution, stratigraphic positions and thicknesses of favorable formations or parts thereof, and structure. More specific computations of reserves should be left to special commodity surveys, as and if justified by current needs for such data.

When estimates of quantity are required they should be expressed with respect to workable depths; these are in turn related to topographic features. Where pit quarrying would be required, as for steeply inclined beds or massive deposits such as granites, an arbitrary depth, for example 100 feet, may be assumed; but the significance of this limitation should be made clear. For approximately horizontal tabular deposits the thickness of the workable bed is used.

For statistical purposes rough construction stone (including rubble) is reported in short tons, paving blocks by number or short tons, and all other dimension stones (cut, mill blocks, slabs, monumental, curbing, and flagging) by volume (cubic feet or yards). Conversion from volume to weight may be calculated by using the following approximate factors, but unless instructed otherwise according to purpose of his project, the field geologist will rarely need to report resources by weight.

The following are apparent specific gravities of common building stones, as reported by the U.S. Bureau of Standards (Kessler, 1919; Kessler and Sligh, 1927).

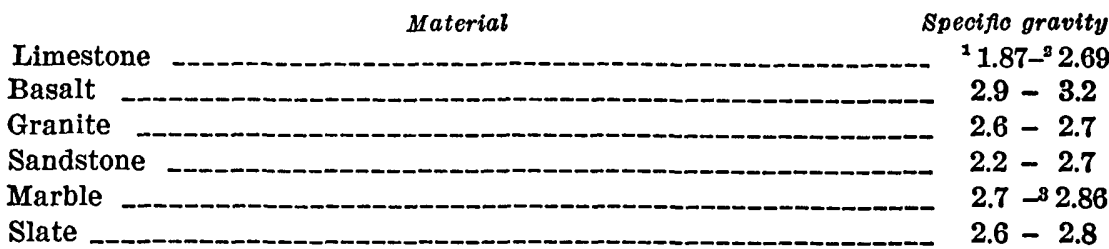

1 Porosity, 31 percent.

2 Porosity, 1 percent.

3 Dolomite.

These values were determined experimentally for groups of established commercial stones. 
For general computations the following approximate average weights in pounds per cubic foot may be used.

\begin{tabular}{|c|c|c|}
\hline \multirow{2}{*}{ Material } & \multicolumn{2}{|c|}{ Weight (lb per cu ft) } \\
\hline & Average & Range \\
\hline $\begin{array}{l}\text { Granite. } \\
\text { "Black granite" (basalt, gabbro, etc.) } \\
\text { Sandstone } \\
\text { Quartzite } \\
\text { Limestone } \\
\text { Marble } \\
\text { Slate }\end{array}$ & $\begin{array}{r}164 \\
185 \\
1141 \\
162 \\
2155 \\
170 \\
169\end{array}$ & $\begin{array}{r}180-200 \\
130-165 \\
160-165 \\
140-175 \\
168-179 \\
\end{array}$ \\
\hline
\end{tabular}

1 Varies with porosity.

Varies with porosity and dolomitic content.

- Highest value for dolomite marbles.

\section{STANDARD DEFINITIONS OF TERMS RELATING TO NATURAL BUILDING STONES}

American Society for Testing Materials (1952, ASTM designation C 119-50) "Standard Definitions Relating to Natural Building Stones" 1 are given below. This standard [adopted, 1927; revised, $\left.1948,1950^{2}\right]$ is issued under the fixed designation $\mathrm{C} 119$; the final number indicates the year of original adoption or, in the case of revision, the year of last revision.

\section{GRANITE}

Granite (scientific definition) $.^{3}-\mathrm{A}$ true granite is a visibly granular, crystalline rock of predominantly interlocking texture, composed essentially of alkalic feldspars (note 1) and quartz. Feldspar is generally present in excess of quartz, and accessory minerals (chiefly micas, hornblende, or more rarely pyroxene) are commonly present. The alkalic feldspars may be present (1) as individual mineral species, (2) as isomorphous or mechanical intergrowths with each other, or (3) as chemical intergrowths with the lime feldspar molecule (note 2), but $80( \pm 3)$ percent of the feldspar must be composed of the potash or soda feldspar molecules.

Note 1: Alkalic feldspars.-This term includes feldspar species commonly known to petrologists as orthoclase, microcline, albite, and oligoclase in which the ratio of soda feldspar molecule to lime feldspar molecule is not less than 80 percent, or intermediate

\footnotetext{
1 Under the standardization procedures of the Society, these definitions are under the jurisdiction of the ASTM Committee C-18 on Natural Bullding Stones.

2 Prior to adoption as standard, the definition of the term "slate" was published as tentative from 1926 to 1927 . The tentative revision Issued in 1948 in the form of a separate tentative was further revised and added to the standard in 1950 .

${ }^{3}$ As the scientific definition of granite is more restricted as to mineralogic composition than is the definition of commercial (building) granite, both are presented herein for purposes of comparison.
} 
varieties or mixtures of these species. The potash and soda feldspar molecules are recognized as being represented respectively by the empirical chemical formula $\mathrm{KAlSi}_{3} \mathrm{O}_{3}$ (orthoclase or microcline molecule), and $\mathrm{NaAlSi}_{3} \mathrm{O}_{3}$ (ablite molecule).

Note 2: Lime feldspar molecule.-The lime feldspar molecule is recognized as being represented by the empirical chemical formula $\mathrm{CaAl}_{2} \mathrm{Si}_{2} \mathrm{O}_{3}$ (anorthite molecule). Isomorphous mixtures of this molecule with the albite molecule occur in all proportions and comprise the group known to mineralogists as the plagioclase, or limesoda feldspars.

Note 3: Certain established species of rocks similar in texture and closely related in composition are included in the category of commercial granite.

Commercial (building) granite. ${ }^{3}$-This term includes granite (as defined above), gneiss (note 1), gnessic granite, granite gneiss, and the rock species known to petrologists as syenite, monzonite, and granodiorite, species intermediate between them, the gneissic varieties and gneisses of corresponding mineralogic compositions and the corresponding varieties of porphyritic textures. The term "commercial" granite shall also include other feldspathic crystalline rocks of similar textures, containing minor amounts of accessory minerals, used for special decorative purposes, and known to petrologists as anorthosite and laurvikite.

Note 1: Gneiss.-A foliated crystalline rock composed essentially of silicate minerals with interlocking and visibly granular texture, and in which the foliation is due primarily to alternating layers, regular or irregular, of contrasting mineralogic composition. In general, a gneiss is characterized by relatively thick layers as compared with a schist. According to their mineralogic compositions gneisses may correspond to other rocks of crystalline, visibly granular, and interlocking texture, such as those included under the defnition of commercial granite, and may then be known as granitegneiss, etc., if strongly foliated, or gneissic granite if weakly foliated.

Noте 2: Black granite.-Rock species known to petrologists as diabase, diorite, gabbro, and intermediate varieties are sometimes quarried as building stone, chiefly for ornamental use, and sold as "black granite." As dimension blocks or slabs they are valued specifically for their dark gray to black color when polished. Scientifically, they are far removed in composition from true granites though they may be satisfactorily used for some of the purposes to which commercial granites are adapted. They posses an interlocking crystalline texture, but unlike granites, they contain little or no quartz or alkalic feldspar, and are characterized by an abundance 
of one or more of the common black rock-forming minerals (chiefly pyroxenes, hornblende, and biotite.)

ITMESTONE

Limestone.-A rock of sedimentary origin (including chemically precipitated material) composed principally of calcium carbonate or the double carbonate of calcium and magnesium (dolomite molecule).

NoTE.-Recrystallized limestones and compact, dense, relatively pure microcrystalline varieties, that are capable of taking a polish are included in commercial marbles.

Calcite limestone.-A limestone containing not more than 5 percent of magnesium carbonate.

Dolomite-A limestone containing in excess of 40 percent of magnesium carbonate as the dolomite molecule.

Magnesian (dolomitic) limestone.-A limestone containing not less than 5 nor more than 40 percent of magnesium carbonate.

Travertine.-Variety of limestone regarded as a product of chemical precipitation from hot springs. Travertine is cellular with the cells usually concentrated in thin layers that display a stalactitic structure. Some that take a polish are sold as marble, and may be classified as travertine marble under the class of commercial marble.

MARBLE

Marble (scientific definition).-A metamorphic (recrystallized) limestone composed predominantly of crystalline grains of calcite or dolomite or both, having interlocking or mosaic texture.

Commercial marble.-A crystalline rock composed predominantly of one or more of the following minerals: calcite, dolomite, or seppentine, and capable of taking a polish.

Calcite marble.-A crystalline variety of limestone containing not more than 5 percent of magnesium carbonate.

Dolomite marble.-A crystalline variety of limestone, containing in excess of 40 percent of magnesium carbonate as the dolomite molecule.

Magnesian (dolomitic) marble.-A crystalline variety of limestone containing not less than 5 nor more than 40 percent of magnesium carbonate as the dolomite molecule.

Onyx marble.-A dense crystalline form of lime carbonate deposited usually from cold-water solutions. Generally translucent and shows a characteristic layering due to mode of accumulation.

Travertine marble.-Under Limestone, see Travertine.

Serpentine marble.-A marble characterized by a prominent amount of the mineral serpentine. 
Verd antique.-A marble composed chiefly of massive serpentine and capable of being polished. It is commonly crossed by veinlets of other minerals, chiefly carbonates of calcium and magnesium.

\section{GREENSTONE}

Greenstone.-Includes rocks that have been metamorphosed or otherwise so altered that they have assumed a distinctive greenish color owing to the presence of one or more of the following minerals: chlorite, epidote, or actinolite.

\section{SANDSTONE}

Sandstone.-A consolidated sand in which the grains are composed chiefly of quartz or quartz and feldspar, of fragmental (clastic) texture, and with various interstitial cementing materials, including silica, iron oxides, calcite, or clay.

Bluestone.-A dense, hard, indurated, fine grained feldspathic sandstone, most of which splits easily into thin, smooth slabs. It is commonly dark or slate gray but the term is applied to all varieties irrespective of color.

Brownstone.-A sandstone of characteristic brown or reddish-brown color that is due to a prominent amount of iron oxide as interstitial material, such aș the Longmeadow sandstone (Massachusetts), Portland stone (Connecticut), or Hummelstown (Pennsylvania) sandstone.

Conglomerate.-A rock made up of worn and rounded pebbles of various sizes cemented as in sandstone. It includes varieties locally known as puddingstone.

Note.-If the pebbles are angular, it is called breccia.

Freestone.-A sandstone that splits with equal ease in any direction and dresses easily.

Quartzite.-A quartz rock derived from sandstone, composed dominantly of quartz, and characterized by such thorough induration, either through cementation with silica or through recrystallization, that it is essentially homogeneous and breaks with vitreous surfaces that transect original grains and matrix or interstitial material with approximately equal ease. Such a stone possesses a very low degree of porosity and the broken surfaces are relatively smooth and vitreous as compared with the relatively high porosity and the dull, rough surfaces of sandstone.

SLATE

Slate.-A microgranular metamorphic rock derived from argillaceous sediments, and characterized by an excellent parallel cleavage en- 
tirely independent of original bedding, by which cleavage the rock may be split easily into relatively thin slabs.

Note 1.-The essential mineral constituents are white mica (chiefly sericite) and quartz. Accessory constituents may be black mica (biotite), chlorite, hematite, carbonates, magnetite, apatite, clay, andalusite, barite, rutile, pyrite, feldspar, zircon, tourmaline, and graphite or other carbonaceous matter.

Note 2.-Igneous slates because of their rare occurrence and insignificant commercial importance are not covered in this definition.

\section{TEXTURES}

Texture.-The grain pattern, relating to sizes, shapes, and mutual relations of component grains or crystals, as equigranular (grains of approximately same sizes), inequigranular (grains of markedly unequal sizes); porphyritic (relatively large grains of one or more mineral components in a ground-mass of markedly finer texture); interlocking (in which grains with irregular boundaries interlock by mutual penetration) ; mosaic or granulitic (closely packed grains with smooth to moderately irregular, noninterlocking mutual boundaries); clastic (naturally cemented fragmental grains but without interlocking or mosaic relations).

NoTE.-Rocks of interlocking texture may possess a mosaic texture in part, but the interlocking character of grains is a controlling or predominant textural feature. The interlocking texture is typified by granite and other granitoid rocks.

\section{LIST OF STANDARD METHODS OF TEST AND SPECIFICATION}

Listed below are standard methods of test for natural building stones, as adopted by the American Society for Testing Materials, 1916 Race Street, Philadelphia 3, Pa. Printed copies of each are available from the society.

Compressive strength of natural building stone (C 170-50)

Water absorption of slate (C 121-48)

Modulus of rupture (C 99-52)

Flexure testing of slate; modulus of rupture, and modulus of elasticity (C 120-52)

Absorption and bulk specific gravity (C 97-47)

Abrasion resistance of stone subjected to foot traffic (C 241-51)

Durability of slate for roofing (C 217-48T)

Weather resistance of natural slate (C 217-56 T)

Combined effect of temperature cycles and weak salt solutions on natural building stone (C 218-48T) 
The following tentative specification is also available; it is currently (January 1958) tentative and undergoing review by the Society; it is, therefore, subject to revision before being adopted as a standard: Tentative specification for roofing slate (C 406-57T).

Proposed specifications for granites, marbles, sandstones, and limestones are currently being devised.

In general, proposed specifications remain in tentative status for at least 2 years before being raised to standard status.

Symbols in parenthesis indicate the society's designation; the first symbol, as C 406, indicates the fixed designation, the second, as 57, indicates the year of adoption ( $T$, if tentative).

\section{SELECTED REFERENCES}

American Society for Testing Materials, 1952, Book of ASTM Standards, part 3: Philadelphia, Pa., p. 891-893.

Baker, I. O., 1914, A treatise on masonry construction, 10th ed.: New York; John Wiley and Sons, p. 279-281.

Bowles, Oliver, 1917, Sandstone quarrying in the United States: U. S. Bur. Mines Bull. 124.

1934, The stone industries: New York, McGraw-Hill Book Co. 1955, Slate: U.S. Bur. Mines Inf. Circ. 7719.

British Standards Institution, 1957, Glossary of terms for stone used in building: London.

Dale, T. N., 1898, The slate belt of eastern New York and western Vermont: U.S. Geol. Survey 19th Ann. Rept., pt. 3.

1912, The commercial marbles of western Vermont: U.S. Geol. Survey Bull. 521.

1923, The commercial granites of New England: U.S. Geol. Survey Bull. 738.

Dale, T. N., and others, 1914, Slate in the United States: U.S. Geol. Survey Bull. 586.

Eckel, E. C., 19i2, Building stones and clays: New York, John Wiley and Sons. Goddard, E. N., chm., and others, 1948, Rock-color chart: Washington, Natl. Research Council; republished by Geol. Soc. America, 1951.

Howe, J. A., 1910, The geology of building stones: London, Edward Arnold.

Julian, A. A., 1884, The durability of building stones in New York City and vicinity: U.S. Dept. Commerce 10th Census, p. 364-393.

Kessler, D. W., 1919, Physical and chemical tests on the commercial marbles of the United States: U.S. Bur. Standards Tech. Paper 123. 1926, Permeability of Stone: U.S. Bur. Standards Tech. Paper 305. 1931, Bibliography on weathering of natural stones: Am. Soc. for Testing Materials Proc., v. 31, pt. 2, p. 804-813.

1932, Physical properties and weathering characteristics of slate: U.S. Bur. Standards Research Paper 447.

Kessler, D. W., and Sligh, W. H., 1927, Physical properties of the principal commercial limestones used for building construction in the United States: U.S. Bur. Standards Tech. Paper 349.

Kessler, D. W., Insley, Herbert, and Sligh, W. H., 1940, Physical, mineralogical, and durability studies on building and monumental granites of the United States: U.S. Bur. Standards Research Paper 1320. 
Loughlin, G. F., 1929, Indiana oölitic limestone: U.S. Geol. Survey Bull. 811-C. Merrill, G. P., 1903, Stones for building and decoration, 3d ed.: New York, John Wiley and Sons.

Pepper, J. F., DeWitt, Wallace, Jr., and Demarest, D. F., 1954, Geology of the Bedford shale and Berea sandstone in the Appalachian basin: U.S. Geol. Survey Prof. Paper 259.

Pettijohn, F. J., 1929, Sedimentary rocks: New York, Harper and Brothers, p. 13.

Richardson, C. H., 1917, Building stones and clays: Syracuse, N. Y., Syracuse Univ. Book Store.

Ries, Heinrich, 1912, Building stones and clay products : New York, John Wiley and Sons.

Schaffer, R. J., 1933, The weathering of natural building stones: London, Dept. Sci. Ind. Research.

U.S. Bureau of Mines, 1927-34, Mineral resources of the United States, 1924-31: Washington, U.S. Govt. Printing Office. ing Office.

U.S. Geological Survey, 1911-27, Mineral resources of the United States, 191023: Washington, U.S. Govt. Printing Office. 1932, Geologic map of the United States: Washington, U.S. Geol. Survey.

Weidman, P. A., 1942, The Berea sandstone of the Cleveland area: Ohio State Univ. Eng. Exp. Sta. News, v. 14, no. 5, p. 14-21. 


\section{INDEX}

Page

A brasive hardness.

Absorption and porosity

$27,30-31$

Acknowledgments.

Architectural color, defined

determination

Ashlar, defined.

use

Atlantic and Gulf Coastal Plains. $27,31-33,39,47$

and Gulf Coastal Plains.-(1)

Basalt, specific gravity weight.

Bedford oolitic limestone

Berea sandstone

"Berea sandstone $61-62 ;$ pl. 7

Blackboard slat

Blind seams

36,$62 ;$ pl. 7

8

Bluestone....... $7,13,73$

Bowling Green oolitic limestone..........- 24

Brick, crushing strength

Brownstone........... 23,60-61, 73

Building stone, defined.

Burlington limestone

Cast stone, crushing strength porosity.

Cipolino marble

Cleavage.

Color

Conglomerate, defined

Construction practices.

Construction stone, defined production.

Cordilleran, Great Basin, and Pacific coastal belt province 24-25; pl. 1

Crushed and broken stone, processing ....... 6 use.

Crushing strength. ... 27-29, 39

Cumberland and Allegheny Plateaus........ 23

Curbing, characteristics...................... 12 production................ 11, 16

Curtain walls; defined..._._._._._. 17

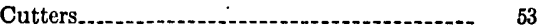

Dedham granodiorite

Dikes, effect....... 54

Dimension slate, production

tests.......... 37

Dimension stone, chemical properties......... 26-27

classification........ 7 defined............. 6

definitions.... 70-74

durability table. .

durability test cycle...

processing .................................. 6

production.

testing methods, list.................. 74

use................. 7-8,66

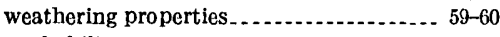

workabllity........ $67-68$
Page

Dimenslon-stone deposits, accessibllity ...... 67

contacts................................... 47

description and classification . .......... 46, 66

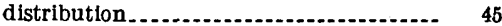

examination schedule........................ 48

industrial evaluation. . . . .

location methods. . .

map interpretation.................... 20,41

operating facility . ....................... 67

origin............... 46

reserve estimates......................... 69

stratigraphic position................. 45

structural geology . ...................... 46

thickness.............. 45

types............. 21

Dolomite, defined .

speciflc gravity

Durability

Eastern crystalline belt............... 22-23; pl. 1

Electrical slate . . . . . .

Fabric, defined.............................. 47

Faults, effect................... 60

Feldspar, alkalic, defined ................... 70-71

lime, formula...... 71

Ferruginous minerals. . . .

Finished stone, use.............. 8

Flagging slate................. 8, 14, 18

Flagstone, characteristics. . ........ 12-13

production . .

Formation names, nomenclature....... 44-45

Fractures, distribution ................ . 9,49,50

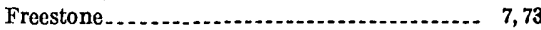

Frost action ......... 59,60,65

"Glass" seam............................... 55

Gneiss, defined.

Grain, defined.......................... 13, 51, 53

Granite, abrasive hardness.................... 31

defined. . . . . 7, 70-72

description. .............................. 48

porosity .............. 32

sheeting .................. 49

specific gravity

transverse strength.................... 29

weight. . . . . . 70

Great Basin, Paciflc coastal belt, and Cordilleran province............ 24-25; pl. 1

Great Plains-central interior-western Appalachian area. ................. 23-24; pl. 1

Greenstone, defined ...................... 7,73

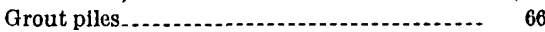

Hairlines . . . . . . . . . .

Hardness... . . . . . . . . . 29-30

Hardway, deflned ........................ 51

Head grain, defined....................... 51

Headers. . . . . . . . . .................... 49; pl. 2 


\begin{tabular}{|c|c|}
\hline Page & Page \\
\hline 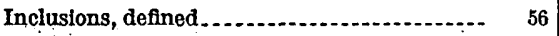 & Rubble, defined................... \\
\hline Inclusions and segregations & production \\
\hline Indiana oolitic limestone.....- & use \\
\hline & 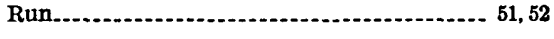 \\
\hline Joints, distribution. ......... & \\
\hline Lake Superior area........... & Sandstone, abrasive hardness............. \\
\hline Lift . . . & crushing strength \\
\hline Limestone, abrasive hardn & defined................. \\
\hline (n........... & described.......... \\
\hline defined..................... & porosity \\
\hline porosity & production........ \\
\hline speciflc gravity. & specific gravity.... \\
\hline transverse strength.... & transverse strength... \\
\hline weight & weight.................. \\
\hline Lithologic classification, com & 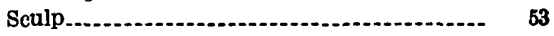 \\
\hline industrial $\ldots . . . . .$. & Seam-face stone \\
\hline Lithologic provinces......... 22-25; pl. 1 & Seneca Red sandstone \\
\hline & Serpentine, abrasive hardness ........... \\
\hline Marble, abrasive hardness.. & crushing strength \\
\hline crushing strength........ & transverse strength... \\
\hline defined........................ & Shakes...................... \\
\hline $48-49$ & Sheet jointing \\
\hline 69 & Sheeting \\
\hline transverse strength & Shelf quarry \\
\hline 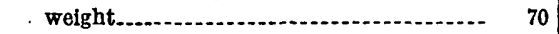 & Slate, abrasive hardness. \\
\hline Mull-stock slate.............. $8,14,18,20$ & classification \\
\hline Missouri Red granite.......... & 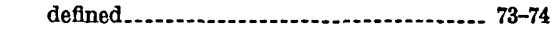 \\
\hline Monumental stone, charact & porosity \\
\hline production & $\begin{array}{l}\text { specific gravity } \\
\text { transverse strength }\end{array}$ \\
\hline Niagara limestone................ & $\begin{array}{l}\text { types. See particular type of slate. } \\
\text { weight...... }\end{array}$ \\
\hline Onyx & Slope curbing, defined.................... \\
\hline Orbicules, defined & Spar \\
\hline Ornamental stone, charactel istics............... & Starts........ \\
\hline Overburden, defined........... & Statuary marble, defined.............. 11, 49 \\
\hline removal............... & Statuary stone, characteristics............... 11 \\
\hline & Stone, defined. \\
\hline $\begin{array}{l}\text { Paciflc coastal belt, Cordilleran, and Great } \\
\text { Basin province }\end{array}$ & $\begin{array}{l}\text { types. See particular type of stone. } \\
\text { Stone industry, business cycles............ } 15,18-20\end{array}$ \\
\hline Paving blocks, defined........... 13 & history \\
\hline . production. & production. \\
\hline Porosity ąd absorption..... & 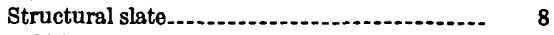 \\
\hline Prospecting & Sulfide minerals, effect................... 61-62,63 \\
\hline Purpose and scope. & Texture, deflned............................ 47, 74 \\
\hline Quarry sizes_................. & Topography \\
\hline Quarry water, defined............ & Toughness (tenacity) \\
\hline Quartzite, crushing strength..... & Transverse strength \\
\hline ; defined & Traprock \\
\hline$\therefore$ porosity & Travertine \\
\hline 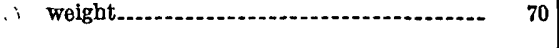 & Valley and Ridge physiographic province..... 23 \\
\hline Random ashlar, & Veins, effect.-......... 54-55 \\
\hline Rift, defined..................... & Veneer, ashlar-type-a $\quad 9$ \\
\hline Riprap, defined............... & Vents \\
\hline Rock, defined. & Verd antique...... 7,55,73 \\
\hline Rock-color chart.................... & Waste disposal... \\
\hline Rock-faced surface, defined........................ & Weathering, chemical. \\
\hline Roofing slate & physical. \\
\hline Rough building stone.......... & \\
\hline Roxbury conglomerate. & Yule marble......... \\
\hline
\end{tabular}

